\title{
The Zebrafish Annexin Gene Family
}

\author{
Steven A. Farber, ${ }^{1,2}$ Robert A. De Rose, ${ }^{1}$ Eric S. Olson, and Marnie E. Halpern \\ Department of Embryology, Carnegie Institution of Washington, Baltimore, Maryland 21210, USA
}

\begin{abstract}
The Annexins (ANXs) are a family of calcium- and phospholipid-binding proteins that have been implicated in many cellular processes, including channel formation, membrane fusion, vesicle transport, and regulation of phospholipase $\mathrm{A}_{2}$ activity. As a first step toward understanding in vivo function, we have cloned 11 zebrafish anx genes. Four genes (anx1a, anx2a, anx5, and anxlla) were identified by screening a zebrafish cDNA library with a Xenopus anx2 fragment. For these genes, full-length cDNA sequences were used to cluster 212 EST sequences generated by the Zebrafish Genome Resources Project. The EST analysis revealed seven additional anx genes that were subsequently cloned. The genetic map positions of all 11 genes were determined by using a zebrafish radiation hybrid panel. Sequence and syntenic relationships between zebrafish and human genes indicate that the 11 genes represent orthologs of human $a n x 1,2,4,5,6,11,13$, and suggest that several zebrafish anx genes resulted from duplications that arose after divergence of the zebrafish and mammalian genomes. Zebrafish anx genes are expressed in a wide range of tissues during embryonic and larval stages. Analysis of the expression patterns of duplicated genes revealed both redundancy and divergence, with the most similar genes having almost identical tissue-specific patterns of expression and with less similar duplicates showing no overlap. The differences in gene expression of recently duplicated anx genes could explain why highly related paralogs were maintained in the genome and did not rapidly become pseudogenes.
\end{abstract}

Sequences of all zebrafish anx genes described in this paper have been deposited in GenBank. The accession nos. are as follows: anxla, AY178793; anxlb, AY178794; anx1c, AY178795; anx2a, AY178796; anx2b, AY178797; anx4, AY178798; anx5, AY178799; anx6, AY178800; anx11a, AY178801; anx11b, AY178802; and anx13, AY178803.

Eleven Annexin (ANX) proteins have been identified in vertebrates (ANX1-7, 9, 11, 13, and 31). ANXs have also been identified in many other organisms, including plants (Smallwood et al. 1990a,b), Hydra vulgaris (Schlaepfer et al. 1992), Dictyostelium discoideum (Bonfils et al. 1994), Giardia lamblia (Fiedler and Simons 1995), Caenorhabditis elegans (Creutz et al. 1996), and Drosophila melanogaster (Johnston et al. 1990). The defining characteristics of all ANXs is that they share a highly conserved 70-amino acid domain that is repeated four to eight times, and they have the ability to bind anionic phospholipids in the presence of calcium (with the exception of ANX31, which lacks the calcium binding site; Moss 1992). The ANXs are the largest group of eukaryotic calcium-binding proteins that do not contain the E-F hand calcium-binding motif (Smith and Moss 1994). ANXs contain a highly divergent N-terminal domain that can vary from ten to hundreds of amino acids and is thought to confer unique functions to given family members (Fig. 1). Within the N-terminal domain of a number of ANXs, there are conserved tyrosine kinase (EGF receptor) and protein kinase C (PKC) sites that are phosphorylated during oncogenic transformation (Glenney Jr. 1985; de Coupade et al. 2000).

The function of this evolutionarily conserved family of proteins remains poorly understood. Studies on cultured cells suggest that ANXs function in a broad range of physiological processes (for a review, see Seaton 1996). For example, it has long been known that ANXs inhibit phospholipases in vitro

'Present address: Department of Microbiology and Immunology, Kimmel Cancer Center, Thomas Jefferson University, Philadelphia, PA 19107, USA.

${ }^{2}$ Corresponding author.

E-MAIL sfarber@lac.jci.tju.edu; FAX (215) 923-7144.

Article and publication are at http://www.genome.org/cgi/doi/10.1101/ gr.479603.
(Huang et al. 1986; Davidson et al. 1987, 1990), and more recently, two ANXs (I and V) have been shown to inhibit phospholipase A2 in living cells (Kim et al. 1994; Croxtal et al. 1996). ANXs can also form volume-activated chloride currents (Nilius et al. 1996) and play a role in membrane fusion and vesicle transport (Bandorowicz-Pikula and Pikula 1998). During exocytosis, ANXs promote the aggregation of phospholipid membranes (Emans et al. 1993; Konig et al. 1998; Raynor et al. 1999), whereas arachidonic acid, which is released from membrane phospholipids by phospholipase A2 activity, promotes membrane fusion (Creutz 1981).

A number of studies have examined the evolutionary history of this gene family (Morgan and Fernandez 1997). Analyses of the gene structure of numerous ANXs have revealed a highly conserved intron-exon organization (for a review, see Smith and Moss 1994). Phylogenetic studies indicate that vertebrate ANX paralogs emanated from a common ancestor 800 million years ago and are now dispersed throughout the genome (Morgan and Fernandez 1997). The observation that ANXs are evolving at different rates suggests that paralogs have nonoverlapping functions (Morgan and Fernandez 1997; Morgan and Pilar Fernandez 1997; Morgan et al. 1999). The zebrafish (Danio rerio) genome has been subject to a round of duplication some 100-400 million years ago, after the divergence of fish and mammalian ancestors, resulting in an $\sim 30 \%$ increase in the total number of genes (Postlethwait et al. 1999). Thus, the zebrafish provides the opportunity to examine why duplicated genes remain fixed in the genome as opposed to becoming pseudo genes.

This report describes the cloning and sequencing of zebrafish orthologs to vertebrate ANXs 1, 2, 4, 5, 6, 11, and 13 . Expression of the anx genes during embryogenesis was examined by in situ hybridization not only to characterize each zebrafish ANX, but to compare the expression of recently du- 


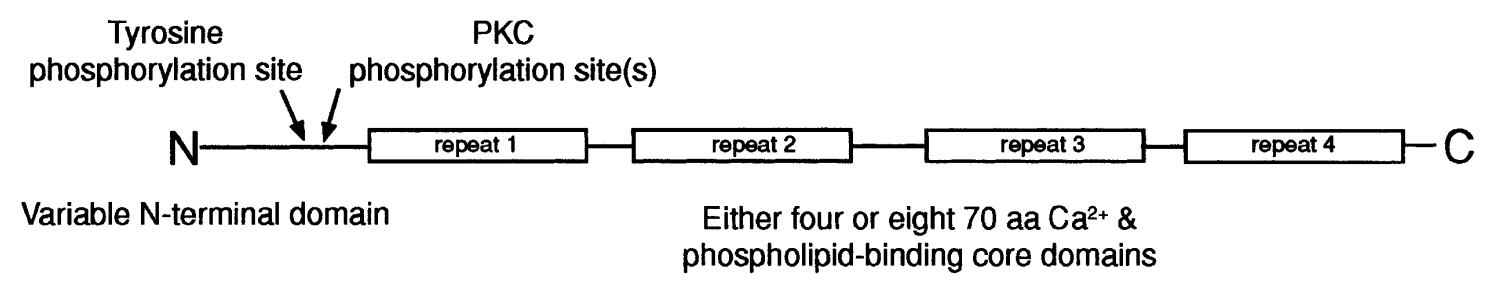

Figure 1 Canonical ANX structure. The N-terminal domains of ANX paralogs are highly variable, with the exception of highly conserved phosphorylation domains. At least two of the four ANX repeats are required to bind $\mathrm{Ca}^{2+}$ and phospholipid.

plicated gene paralogs. The nonoverlapping expression of duplicated genes suggests that the divergence of tissue specific functions drives the continued presence of ANX paralogs in the zebrafish genome.

\section{RESULTS}

Four zebrafish anx genes (anx1a, anx2a, anx5, and anx11a) were identified by low-stringency hybridization of a postsomite cDNA library by using a Xenopus laevis anx 2 probe. From comparisons with these genes, we identified seven additional anx genes by BLAST searches of zebrafish ESTs (see Table 1). Sequence alignments of the 11 zebrafish anx genes with mammalian anx genes revealed that three zebrafish anx genes were homologous with human anx1, two were homologous with human anx2, and two were homologous with human anx11 (Fig. 2).

The predicted zebrafish ANX1b and ANX1c proteins are almost identical in their core repeat domain (97\% identity in the first repeat), yet highly divergent in the N-terminal domain (33\% identity). Only ANX1c contains the typical conserved EGF receptor and PKC phosphorylation sites observed in the N-terminal regions of mammalian ANX1 proteins (Fig. 2). Similarly, the predicted ANX2a and ANX2b proteins show higher identity in the repeat domain than in the N-terminal domain even though both paralogs contain the conserved N-terminal PKC phosphorylation site (Fig. 2). The ANX11 paralogs contain $\mathrm{N}$ termini rich in glycine, glutamine, and proline, characterized by a GYPPQPG repeat that is similar to that found in mammalian ANX11 proteins (Tokumitsu et al. 1992). As is the case for the other duplicated genes, the Nterminal regions of ANX11a and ANX11b are more divergent than are the repeat domains.

Despite the prevailing view that the $\mathrm{N}$-terminal regions can be used to identify specific ANX family members, our analysis indicated that only the amino acids in the repeat domain were useful for phylogenetic analysis. With the exception of ANX4, all the zebrafish ANX N-terminal domains show little or no overall homology with their mammalian counterparts. For example, in the N-terminal region of ANX5, only the GTV motif is conserved between species (zebrafish, medaka, human, mouse, and chick), whereas most of the first repeat sequence is identical. The lack of homology in the Nterminal region of even closely related ANXs indicates that comparisons of this region would be less useful in elucidating the evolutionary relationships between fish ANXs. In contrast, the slow rate of mutation accumulation in the repeat region makes it useful for locating sequence similarities.

The phylogenetic tree of zebrafish, medaka (Oryzias latipes), pufferfish (Fugu rubripes), and human ANXs constructed by using only the amino acid sequence of the first ANX repeat reveals a close relationship between several pairs of duplicated zebrafish genes (Fig. 3). The $a n \times 1 b$ and anx1c genes are the most closely related of all the duplicated paralogs. The phylogenetic analysis also suggests that we have identified orthologs to each of the four previously identified medaka ANXs. Medaka Max 1 is a likely ortholog of zebrafish ANX4, Max 2 is an ortholog of ANX5, Max 3 is an ortholog of ANX1, and Max 4 is an ortholog of ANX11.

To determine the timing of the duplication event observed in zebrafish, we searched the public databases for additional medaka anx sequences and identified 13 ESTs (data not shown). All but one of these new sequences cluster with the four previously published medaka anx genes (Max1 through Max4) already represented on the phylogenetic tree. The remaining clone was not a recent duplicate of these previously identified genes. Thus, the evolutionary relationship between the duplicated genes in these two species was not compared because of the paucity of medaka EST sequences. BLAST searches of fugu ESTs identified orthologs for zebrafish ANXs. Interestingly, phylogenetic analysis of these data (Fig. 3) suggests that fugu ANX1 and ANX2 paralogs were also duplicated, indicating that the duplication occurred in at least a subgroup of the Teleostei (Clupeocephala).

\section{Syntenic Relationships Between Human and Zebrafish anx Genes}

Because the N-terminal sequences of fish ANXs are considerably different from their mammalian counterparts, it is conceivable that zebrafish anx genes could be misidentified. To confirm that the 11 zebrafish anx genes were correctly assigned, we mapped the chromosomal position of each gene and, on the basis of the surrounding mapped genes, determined whether the given zebrafish anx gene showed conserved syntenies with its putative human ortholog. Ten of the 11 anx genes mapped to syntenic clusters containing the human ortholog (Fig. 4). For example, zebrafish anx5 is surrounded by genes (mel1ar, fga, and $s c 4 m o l$ ) that also map near the human anx5 ortholog (Fig. 4D), indicating that the zebrafish gene was correctly identified.

The mapping data for the anx 1 genes indicate that all three genes lie on zebrafish linkage group (LG) 5 . They probably arose by tandem duplication (Fig. 4A) because $a n x 1 b$ and anx 1c map very close to each other (e.g., beyond the resolution of the radiation hybrid panel). Zebrafish anx $1 c / a n x 1 b$ are closely linked to the zebrafish trk gene; this anx1/trk syntenic cluster is preserved in humans (Fig. 4A). Of the ANX1 proteins, only ANX1c has both the conserved tyrosine and threonine phosphorylation sites present in the human protein (Fig. 2), suggesting that anx $1 \mathrm{c}$ is the most closely related to human anx1.

Mapping data for the $a n \times 2$ genes reveal the relationship between zebrafish and human chromosomes. The region containing anx $2 a$ is syntenic with a region of human chromosome 15 that contains anx2 (Fig. 4C). However, both zebrafish 
Table 1. Zebrafish Annexin ESTs

\begin{tabular}{|c|c|c|c|c|c|c|c|c|}
\hline Clone & EST & Gene & Clone & EST & Gene & Clone & EST & Gene \\
\hline $\mathrm{fa} 01 \mathrm{~d} 11$ & AA495341 & $1 \mathrm{a}$ & fe15g04 & AW128428 & $1 \mathrm{a}$ & fk86h09 & BE201180 & $1 \mathrm{a}$ \\
\hline $\mathrm{fa01d} 11$ & AA495413 & $1 \mathrm{a}$ & fe16d06 & AW116978 & 6 & $\mathrm{fk} 87 \mathrm{c05}$ & BE200562 & $1 \mathrm{c}$ \\
\hline $\mathrm{fa05d} 11$ & AA495031 & $1 \mathrm{a}$ & fe16d06 & AW128478 & 6 & $\mathrm{fk} 87 \mathrm{c} 05$ & BE201203 & $1 \mathrm{c}$ \\
\hline$f a 05 d 11$ & AA495062 & $1 a$ & fe23g04 & AW059024 & $1^{*}$ & fk87h08 & BE200605 & $1 \mathrm{a}$ \\
\hline fa16b09 & AA606132 & $1 b$ & fe $36 g 11$ & AW117164 & $1 a$ & fk87h08 & BE201325 & $1 a$ \\
\hline fa22e03 & AA605663 & $1 c$ & fe $36 g 11$ & AW128738 & $1 \mathrm{a}$ & fk89e04 & BE200691 & 5 \\
\hline fa66e01 & AA658724 & $2 a$ & fe $37 \mathrm{~d} 07$ & AW128288 & 5 & fk89e04 & BE201296 & 5 \\
\hline fa92b02 & Al330716 & $11 \mathrm{~b}$ & fe $37 d 07$ & AW128788 & 5 & fk93b10 & BE556966 & $1 \mathrm{a}$ \\
\hline fa93d04 & Al331482 & $2 a$ & fi08c10 & AW128143 & 5 & $\mathrm{fk} 95 \mathrm{a} 02$ & BE201562 & $2 a$ \\
\hline fa93d04 & Al332090 & $2 a$ & fi69d08 & AW423191 & 5 & $\mathrm{fk} 96 \mathrm{f12}$ & BE201666 & $1 \mathrm{a}$ \\
\hline fa93g02 & Al331515 & $1 b$ & fi73b04 & AW343140 & $11 a$ & fk97g09 & BE201732 & 4 \\
\hline fa93g02 & Al332162 & $1 b$ & fi89f12 & AW421306 & 3 & fk97g09 & BE557263 & 4 \\
\hline fa97e02 & Al331333 & $1 a$ & fi98b03 & AW466704 & * & fk98d10 & BE201768 & $1 \mathrm{a}$ \\
\hline fa97e02 & Al332264 & $1 \mathrm{a}$ & fi98b03 & AW510130 & * & fk98d10 & BE557304 & $1 \mathrm{a}$ \\
\hline fa98e12 & Al331304 & $2 a$ & $\mathrm{fj} 01 \mathrm{c} 11$ & AW076603 & $4 a$ & fk98f07 & BE201783 & 5 \\
\hline fa98e12 & Al331418 & $2 a$ & fj01c11 & AW077934 & $4 a$ & $\mathrm{fk} 98 \mathrm{f07}$ & BE557319 & 5 \\
\hline fa98f06 & Al331309 & 5 & fj01f04 & AW076623 & $1 \mathrm{~b}$ & $\mathrm{fl02b05}$ & BE201872 & $1 \mathrm{a}$ \\
\hline fa98f06 & Al331423 & 5 & fj01f04 & AW077961 & $1 \mathrm{~b}$ & $\mathrm{fl} 02 \mathrm{~b} 05$ & BE557344 & $1 \mathrm{a}$ \\
\hline fa98g02 & Al331316 & $1 \mathrm{c}$ & fj1 $10 f 10$ & AW184217 & 5 & $\mathrm{fl} 04 \mathrm{a} 05$ & BE201981 & 5 \\
\hline fa98g02 & Al331430 & $1 c$ & fj1 $10 f 10$ & AW203168 & 5 & $\mathrm{fl} 04 \mathrm{a} 05$ & BE557472 & 5 \\
\hline $\mathrm{fb} 01 \mathrm{~d} 04$ & Al331722 & $2 a$ & fj15f01 & AW184537 & $11 b$ & $\mathrm{fl04b02}$ & BE201987 & $1 \mathrm{a}$ \\
\hline $\mathrm{fb} 01 \mathrm{~d} 04$ & Al331746 & $2 a$ & fj15f01 & AW232190 & $11 b$ & $\mathrm{fl04b02}$ & BE557480 & $1 \mathrm{a}$ \\
\hline $\mathrm{fb} 03 \mathrm{~b} 04$ & Al330831 & $1 a$ & fj1 $17 \mathrm{~g} 03$ & AW184689 & $1 \mathrm{c}$ & fl06f05 & BE202117 & $1 \mathrm{c}$ \\
\hline $\mathrm{fb} 04 \mathrm{a} 03$ & Al330976 & $11 \mathrm{~b}$ & fj17g03 & AW232322 & $1 \mathrm{c}$ & $\mathrm{fl} 08 \mathrm{c} 05$ & BE202212 & $2 a$ \\
\hline $\mathrm{fb} 07 \mathrm{f0} 04$ & Al384320 & 5 & fj20f05 & AW202684 & 13 & $\mathrm{fl} 08 \mathrm{c} 06$ & BE557634 & $2 a$ \\
\hline $\mathrm{fb} 07 \mathrm{~g} 04$ & Al396958 & 5 & fj21a04 & AW202707 & $2 a$ & fl09f01 & BE557047 & $1 \mathrm{a}$ \\
\hline $\mathrm{fb} 09 \mathrm{a} 08$ & Al396702 & $4 a$ & fj26b07 & AW232957 & $4 a$ & fl09f01 & BE605432 & $1 \mathrm{a}$ \\
\hline fb09a08 & Al397259 & $4 a$ & fj38d12 & AW280338 & 13 & fl09f01 & BE605432 & $1 \mathrm{a}$ \\
\hline fb10b01 & Al384973 & $1 a$ & fj66c06 & AW077764 & $2 a$ & $\mathrm{fl} 10 \mathrm{e} 03$ & BE557775 & $1 a$ \\
\hline fb10b01 & Al397327 & $1 a$ & fj91c05 & AW421433 & 13 & $\mathrm{fl} 10 \mathrm{e} 03$ & BE605484 & $1 \mathrm{a}$ \\
\hline $\mathrm{fb} 10 \mathrm{c} 06$ & Al384990 & $1 b$ & fj94g06 & AW421231 & $4 a$ & fl1 of08 & BE557784 & $2 a$ \\
\hline fb 11 h07 & Al384429 & $1 b$ & fj94g06 & AW422555 & $4 a$ & $\mathrm{fl} 10 \mathrm{fo} 08$ & BE605491 & $2 a$ \\
\hline fb11h07 & Al384960 & $1 \mathrm{~b}$ & $\mathrm{fk} 02 \mathrm{~d} 05$ & AW566597 & 4 & fl10h06 & BE605504 & $2 a$ \\
\hline $\mathrm{fb} 13 \mathrm{c} 06$ & Al384226 & 5 & $\mathrm{fk} 03 \mathrm{~b} 10$ & AW566666 & $11 a$ & $f \mid 11 d 06$ & BE557821 & $2 a$ \\
\hline $\mathrm{fb} 13 \mathrm{c} 06$ & Al396592 & 5 & $\mathrm{fk} 04 \mathrm{~d} 01$ & AW466773 & $2 a$ & $\mathrm{fl} 11 \mathrm{~g} 03$ & BE557846 & $1 \mathrm{a}$ \\
\hline $\mathrm{fb} 15 \mathrm{~d} 08$ & Al396641 & $1 a$ & $\mathrm{fk} 07 \mathrm{c08}$ & AW466818 & $4 b$ & $\mathrm{fl} 12 \mathrm{f} 08$ & BE605559 & $1 \mathrm{a}$ \\
\hline $\mathrm{fb} 15 \mathrm{~d} 08$ & Al882710 & $1 a$ & fk08h09 & AW466394 & $1^{*}$ & fl1 $14 \mathrm{f07}$ & BE605642 & $2 a$ \\
\hline fb38g11 & Al437194 & $1 \mathrm{c}$ & $\mathrm{fk} 11 \mathrm{a} 01$ & AW510237 & $2 a$ & fl15c09 & BE557930 & $1 \mathrm{c}$ \\
\hline fb38g11 & Al444361 & $1 \mathrm{c}$ & $\mathrm{fk} 22 \mathrm{f0} 3$ & AW566900 & $1 \mathrm{a}$ & $\mathrm{fl} 16 \mathrm{~b} 05$ & BE557967 & $1 \mathrm{a}$ \\
\hline fb40a08 & Al437290 & 13 & $\mathrm{fk} 23 \mathrm{~b} 02$ & AW566526 & $11 \mathrm{~b}$ & $\mathrm{fl} 16 \mathrm{~b} 05$ & BE605673 & $1 a$ \\
\hline $\mathrm{fb} 40 \mathrm{a} 08$ & Al461284 & 13 & fk24a12 & AW567284 & $1 \mathrm{a}$ & $f \mid 17 d 01$ & BE558015 & $1 \mathrm{a}$ \\
\hline fb40h01 & Al444277 & $1 b$ & fk24a12 & AW594790 & $1 a$ & fl17d05 & BE558019 & $2 a$ \\
\hline fb40h03 & Al461328 & $1 \mathrm{~b}$ & fk26b11 & AW567479 & $2 a$ & $\mathrm{fl} 19 \mathrm{~g} 08$ & BE558121 & $2 a$ \\
\hline $\mathrm{fb} 52 \mathrm{~b} 02$ & Al476872 & $2 b$ & fk29a06 & AW567545 & 4 & $f \mid 19 g 08$ & BE605746 & $2 a$ \\
\hline fb57f04 & Al477453 & $2 b$ & fk29a06 & AW595172 & 4 & fl20d09 & BE558162 & $1 \mathrm{a}$ \\
\hline fb59b10 & AW018621 & $2 b$ & $\mathrm{fk} 31 \mathrm{e} 12$ & AW566920 & $2 a$ & $f \mid 20 d 09$ & BE605780 & $1 \mathrm{a}$ \\
\hline $\mathrm{fb} 60 \mathrm{~g} 02$ & Al497488 & $11 \mathrm{~b}$ & $\mathrm{fk} 31 \mathrm{e} 12$ & AW595499 & $2 a$ & $\mathrm{fl} 20 \mathrm{f0} 01$ & BE558169 & $1 \mathrm{a}$ \\
\hline $\mathrm{fb} 65 \mathrm{e} 04$ & Al545799 & $4 a$ & $\mathrm{fk} 36 \mathrm{~g} 03$ & AW595256 & $2 a$ & $\mathrm{fl} 20 \mathrm{f} 01$ & BE605793 & $1 \mathrm{a}$ \\
\hline fb65e10 & Al544742 & $4 a$ & fk40a05 & AW778666 & $1 \mathrm{a}$ & flo8c06 & BE202113 & $2 a$ \\
\hline fb69d06 & Al544877 & $11 a$ & $\mathrm{fk} 65 \mathrm{~d} 07$ & BE016101 & 1a & $\mathrm{fm} 75 \mathrm{~d} 10$ & BF938344 & 13 \\
\hline $\mathrm{fb} 69 \mathrm{~d} 06$ & Al544926 & $11 a$ & $\mathrm{fk} 65 \mathrm{~d} 07$ & BE016572 & $1 \mathrm{a}$ & $\mathrm{fm} 79 \mathrm{e} 05$ & BF938645 & 5 \\
\hline $\mathrm{fb} 71 \mathrm{~b} 11$ & Al545200 & $4 a$ & $\mathrm{fk} 65 \mathrm{f} 01$ & BE016703 & $2 a$ & $\mathrm{fm} 95 \mathrm{~g} 05$ & BG799346 & $1 \mathrm{a}$ \\
\hline $\mathrm{fb} 92 \mathrm{c} 11$ & Al584862 & $11 \mathrm{~b}$ & fk68a10 & BE016198 & $1 \mathrm{a}$ & fm96h08 & BG799431 & $1 \mathrm{a}$ \\
\hline fc09a11 & Al601281 & $11 a$ & fk68a10 & BE016726 & $1 a$ & fp $23 \mathrm{c} 12$ & BG883870 & $11 a$ \\
\hline fc09a11 & Al629060 & $11 a$ & $\mathrm{fk} 68 \mathrm{f07}$ & BE016228 & $2 a$ & fp66e04 & BG739067 & $11 \mathrm{~b}$ \\
\hline fc20a07 & Al658201 & 5 & $\mathrm{fk} 68 \mathrm{f07}$ & BE016768 & $2 a$ & fq90g12 & BG892099 & $2 a$ \\
\hline fc $44 \mathrm{~g} 02$ & Al794466 & $2 a$ & fk69h01 & BE016364 & $1 \mathrm{a}$ & fq92c05 & BG892182 & $1 \mathrm{a}$ \\
\hline fc $44 \mathrm{~g} 02$ & Al883271 & $2 a$ & fk69h01 & BE016847 & $1 \mathrm{a}$ & fq92d07 & BG892191 & $1 \mathrm{a}$ \\
\hline fc $63 \mathrm{e} 05$ & Al883404 & 13 & fk70a12 & BE016380 & $1 \mathrm{a}$ & RZBAA36 & Al964147 & $11 a$ \\
\hline fc65c09 & Al878734 & $2 a$ & fk70a12 & BE016865 & $1 \mathrm{a}$ & RZBAA36 & Al964148 & $11 a$ \\
\hline fc $65 \mathrm{c} 09$ & Al883512 & $2 a$ & fk71a08 & BE016928 & $1 \mathrm{c}$ & zeh0376 & Al353349 & $11 b$ \\
\hline $\mathrm{fc} 65 \mathrm{fo7}$ & Al883535 & $11 \mathrm{~b}$ & $\mathrm{fk} 72 \mathrm{~h} 02$ & BE016998 & 5 & zehl0196 & AW453608 & 5 \\
\hline fc87g05 & Al943258 & $2 a$ & fk75a05 & BE017050 & $1 \mathrm{a}$ & zehl1082 & AW453598 & $1 \mathrm{c}$ \\
\hline fc87g06 & AI965162 & $2 a$ & $\mathrm{fk} 75 \mathrm{a} 05$ & BE017357 & $1 a$ & zehl2341 & AW454928 & $11 \mathrm{~b}$ \\
\hline fc94h04 & Al957567 & $11 \mathrm{~b}$ & $\mathrm{fk} 75 \mathrm{a} 10$ & BE017362 & $1 \mathrm{a}$ & zehn0184 & Al616512 & $4 a$ \\
\hline fc94h04 & Al958668 & $11 \mathrm{~b}$ & $\mathrm{fk} 77 \mathrm{~d} 05$ & BE017181 & 1a & zehn0306 & Al618466 & $1 \mathrm{~b}$ \\
\hline $\mathrm{fd} 25 \mathrm{c} 12$ & Al959209 & $11 a$ & $\mathrm{fk} 81 \mathrm{a} 02$ & BE017610 & $2 a$ & zehn1052 & Al617080 & $2 a$ \\
\hline $\mathrm{fd} 48 \mathrm{fo} 04$ & AW018574 & $4 a$ & fk81g06 & BE017653 & $1 a$ & zehn1601 & Al617459 & $11 b$ \\
\hline $\mathrm{fd} 54 \mathrm{~h} 03$ & BF717976 & 3 & fk84d04 & BE200977 & $2 a$ & zehn2370 & Al617967 & $2 b$ \\
\hline $\mathrm{fd} 59 \mathrm{~g} 04$ & AW018667 & $11 \mathrm{~b}$ & $\mathrm{fk} 84 \mathrm{f04}$ & BE200999 & $1 \mathrm{a}$ & zewp0221 & Al618675 & $1 a$ \\
\hline fd59g04 & AW019090 & $11 \mathrm{~b}$ & fk86h09 & BE017946 & $1 a$ & & & \\
\hline
\end{tabular}

Two hundred twelve ESTs were identified by alignment with cloned zebrafish annexins as of July 15, 2001.

*indicates poor quality sequence that prevented paralog assignment. 


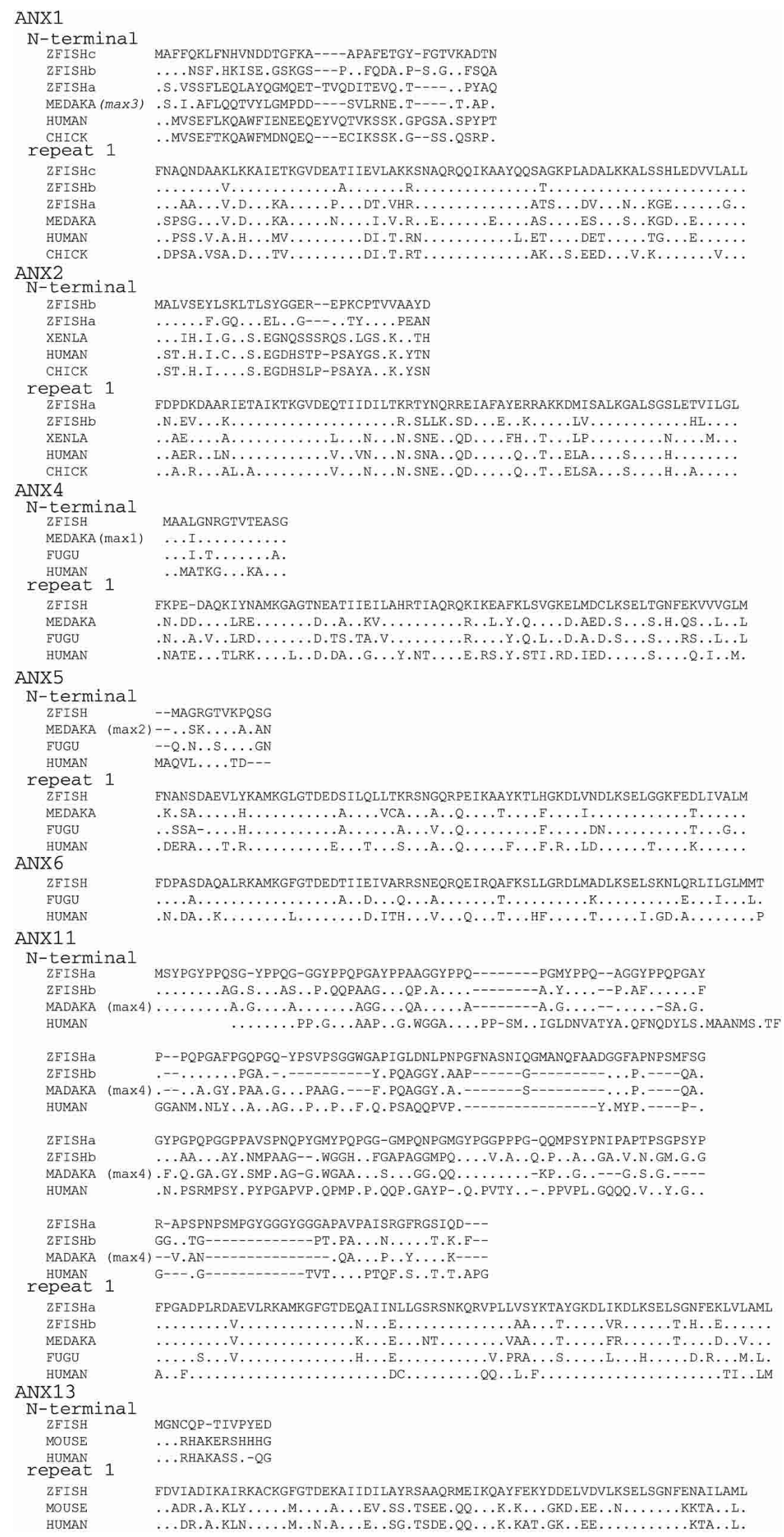

Figure 2 Comparisons of zebrafish ANX amino acid sequences. The corresponding proteins were aligned by using CLUSTALW, revealing significant divergence in their $\mathrm{N}$-terminal domains as opposed to the first core repeat. 


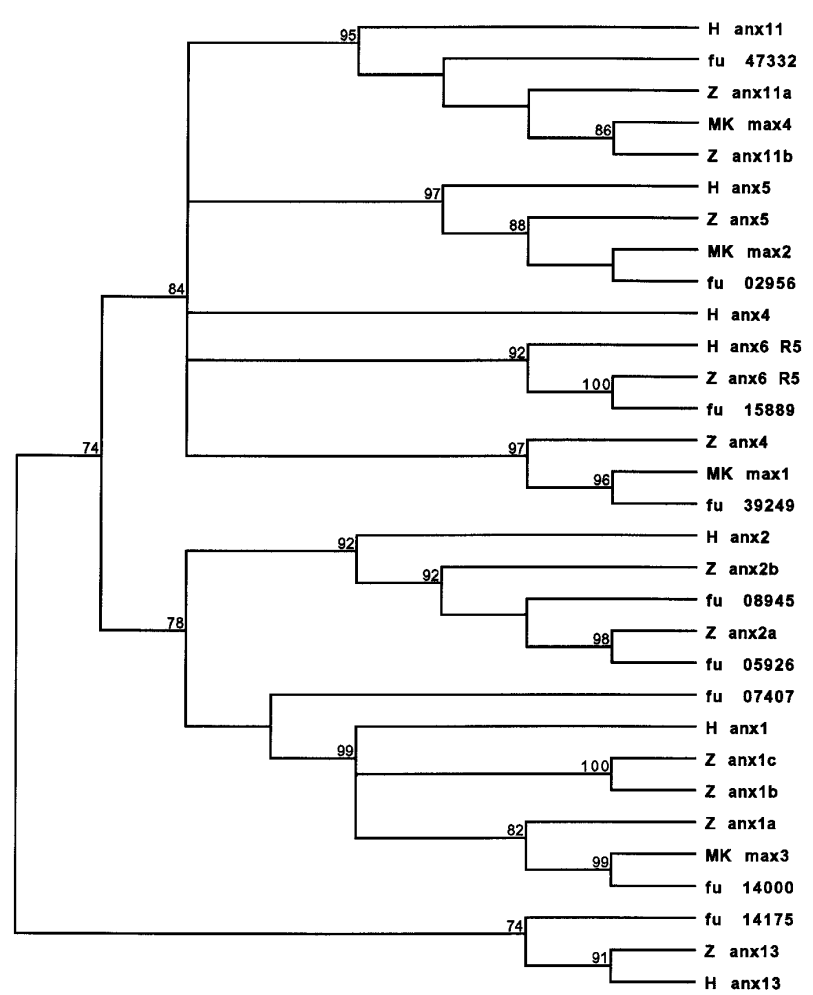

Figure 3 Phylogenetic relationships of the human, zebrafish, pufferfish (Fugu rubripes), and medaka (Oryzias latipes) ANXs. Medaka ANX sequences were obtained from GenBank: max1, CAA72125; $\max 2$, CAA72123; $\max 3, \mathrm{CAA72124;} \max 4, \mathrm{CAA7} 2122$.

anx 2 genes are surrounded by orthologous genes that map to either human chromosome 11 or 15 , suggesting that these clusters of human genes once resided on a single ancestral chromosome that split after divergence of mammalian and zebrafish genomes. The mapping results for zebrafish anx11 genes are more clear-cut, indicating that both paralogs are surrounded by genes with human orthologs that map to the same region on human chromosome 10 (Fig. 4F). These mapping results unequivocally relate mammalian anx genes to those found in zebrafish.

\section{Expression of Zebrafish Genes}

The temporal expression patterns of zebrafish anx genes were examined by whole-mount in situ hybridization and, in some instances, validated by Northern analysis. The three anx1 genes are primarily expressed in the outermost embryonic cells, known as the enveloping layer (Kimmel et al. 1995), during the period ( $\sim 4$ to $9 \mathrm{~h}$ postfertilization [hpf]) when this layer is dividing and migrating over the large yolk cell in a process termed epiboly (Fig. 5A-C). After epiboly is completed and somatogenesis begins, the expression of all three anx1 genes is reduced, as exemplified by expression of anx $1 a$ at the midsomite stage (Fig. 5D) and by Northern analysis (Fig. 5K). By $24 \mathrm{hpf}$, anx 1 transcripts increased primarily in the outer ectoderm, with the expression level of anx 1 a being the highest (Fig. 5E). It is only at this stage that divergence between the paralogous anx1 genes is observed. Not only is the expression of $a n \times 1 b$ and anx $1 c$ reduced compared with anx $1 a$, but anx $1 \mathrm{c}$ is selectively expressed in a small group of cells close to the yolk and posterior to the eyes (Fig. 5F,G). After $80 \mathrm{hpf}$, all three anx genes were expressed in gill arches, epithelium, and fin buds (Fig. 5H,I), but only anx1a was expressed in the cells surrounding the swim bladder (Fig. 5I).

The zebrafish anx2 gene paralogs are significantly more divergent in their core domain as compared with $a n \times 1 b$ and anx1c paralogs (76\% versus 94\%; Fig. 2 ). We also found that the zebrafish anx2 paralogs do not exhibit overlap in their expression patterns (Fig. 6). anx $2 a$ was expressed in the notochord (Fig. 6A) and in a subset of enveloping layer cells (Fig. 6B). Notochord expression was detected at the end of epiboly through early somite stages (Fig. 6C,D), and decreased in an anterior to posterior fashion. By the 21-somite stage, anx2a expression was observed only in the caudal-most notochord (Fig. 6E) and, after $24 \mathrm{hpf}$, in the epithelium and cells around the anus (Fig. 6F). In contrast, $a n \times 2 b$ expression was not observed during early embryonic development (data not shown) and was first detected at $\sim 48$ to $80 \mathrm{hpf}$ in the cells of the intestinal epithelium (Fig. 6G). Transcripts were observed in both the proximal (Fig. $6 \mathrm{H}$ ) and distal segments of the differentiating intestine (Fig. 6I).

The zebrafish anx4 ortholog was expressed during the onset of somatogenesis in the floor plate and in two lateral stripes (Fig. 7A) that most likely correspond to the pronephric duct precursor cells (Drummond et al. 1998). Two-color in situ hybridization with anx4 and draculin, a marker of blood cell precursors (Herbomel et al. 1999), confirmed that the lateral anx4-expressing cells were not hematopoietic precursors (Fig. 7F,G). At the 21-somite stage, anx4 is predominately expressed in floor plate, hypochord, and pronephros (Fig. 7B), a pattern that continues through $24 \mathrm{hpf}$ (Fig. 7C,H). Additionally, at $24 \mathrm{hpf}$, expression was observed in the otolith, glomerulus, pronephric tubules, and pronephric ducts (Fig. 7D). Tissue-specific anx4 expression was assigned on the basis of its similarity with pax2, a previously established marker of pronephros development (Drummond et al. 1998), which also labels these structures. After 70-80 hpf, anx4 was expressed predominantly in the liver and gall bladder (Fig. 7I,J). The expression of anx4 in the pronephros is consistent with its reported role in regulating $\mathrm{Cl}^{-}$conductance in fluid secreting epithelia (Kaetzel et al. 1994).

Zebrafish anx 5 showed the most restricted pattern of expression during embryonic development. During somatogenesis, transcripts were found in the blood islands (21 somites, Fig. 8A) and at the most anterior tip of the embryo (26 somites; Fig. 8B). Cells in the olfactory placodes also expressed anx5 (Fig. 8C). At $24 \mathrm{hpf}$, expression was mostly restricted to the olfactory placodes, hatching gland cells, and anus (Fig. $8 \mathrm{D})$. After $80 \mathrm{hpf}$, expression was maintained in the developing nasal epithelium and in the anus; cells surrounding the swim bladder also expressed anx5. After $120 \mathrm{hpf}$, the cells surrounding the opening to the mouth expressed anx 5 (Fig. $8 \mathrm{E})$, suggesting that these cells were related to the anx5expressing cells observed in the anterior most region at the 26-somite stage (data not shown). Consistent with the RNA in situ gene expression data, Northern analysis of anx5 transcripts revealed a $2.2-\mathrm{kb}$ message that was initially detected at the 22-somite stage (Fig. 8F). Expression was also detected in RNA from 256 cell embryos, a stage prior to the onset of zygotic transcription, indicating some maternal contribution of anx5 RNA to the embryo.

anx 11a expression was observed at the end of gastrulation predominantly in the notochord (Fig. 9A,B). Unlike anx $2 a$, which was also expressed in the developing notochord, there was no enveloping layer expression. As somato-

\section{Genome Research


A

Auman

Chrom. 9

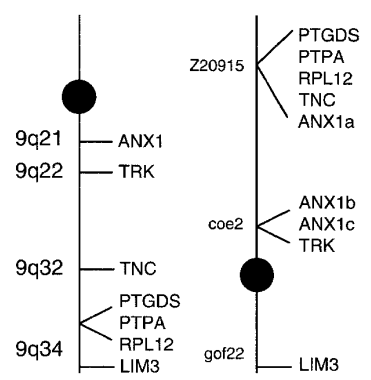

C

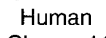

Chrom. 11

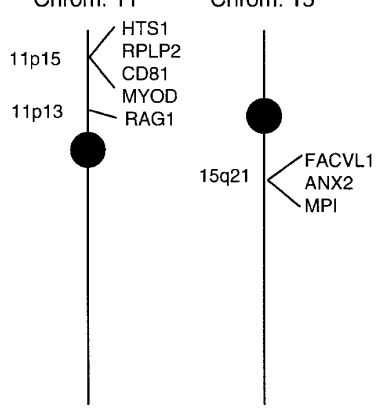

D

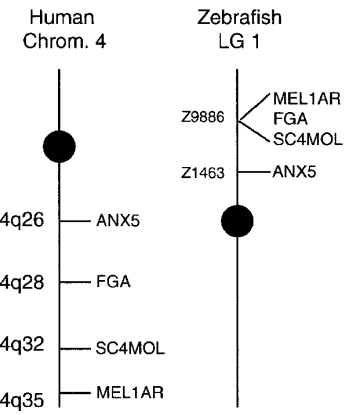

B
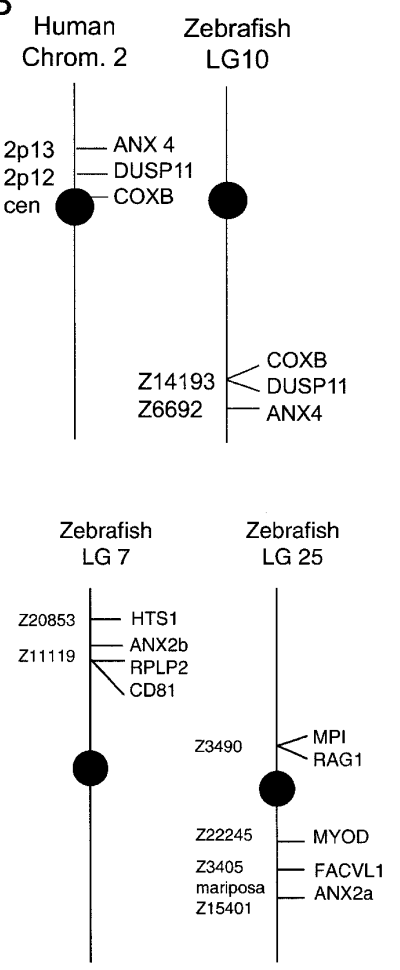

E

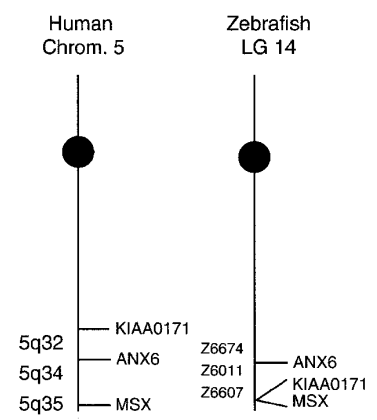

$\mathrm{F}$

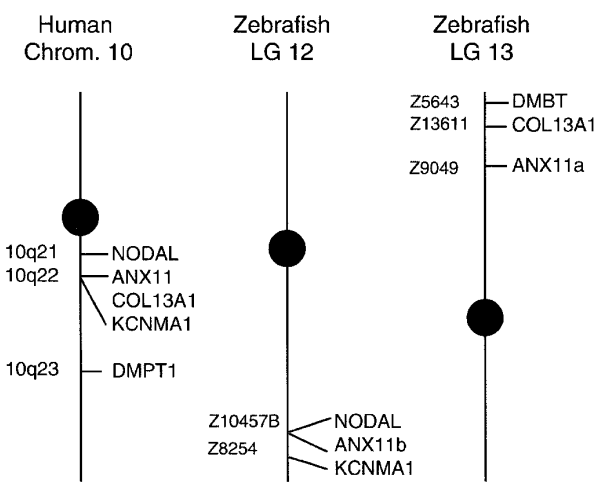

Figure 4 Map positions of human and zebrafish gene orthologs.

genesis advanced, expression was seen to shift from the axial mesoderm to the adaxial mesoderm (cells directly adjacent to the notochord; Fig. 9C). It was previously shown that in the absence of notochord, there is decreased adaxial expression of MyoD, a transcription factor that is known to play a role in myogenesis (Weinberg et al. 1996). To test whether differentiated notochord was similarly required for the adaxial expression of anx11a, no tail embryos, which are known to lack notochord (Halpern et al. 1993), were examined. The transition of anx $11 a$ expression to adaxial cells was unaffected in no tail embryos (Fig. 9D). In wild-type embryos, the shift in expression away from the midline to more lateral structures continued as development proceeded, such that by $24 \mathrm{hpf}$, expression was observed in the paraxial mesoderm, anus, and periderm (Fig. 9E,F). The anx11a paralog, anx11b, was only weakly detected in the notochord of four-somite embryos (data not shown); however, at $24 \mathrm{hpf}$, $a n \times 11 b$ showed strong expression in the periderm similar to anx11a (Fig. 9F). Later in development, anx11a was expressed more intensely in the liver (arrowhead) than in the intestine (arrow; Fig. 9G), the opposite to the expression pattern of anx $11 b$ (Fig. 9H). Northern analysis of anx $11 a$ expression revealed a $2.2-\mathrm{kb}$ message that was detected from the end of gastrulation to the adult stage (Fig. 9I).

The anx6 gene was primarily expressed in somitic mesoderm from the midsomite stages (Fig. 10A) to $24 \mathrm{hpf}$ (Fig. 10B,C). Little expression was detected after $72 \mathrm{hpf}$ (data not shown). anx13 is detected during gastrulation in the notochord and in an area at the anterior-most portion of the embryo in a region called the polster (Fig. 10D,E). At the 21somite stage, anx13 expression was maintained in the notochord and central nervous system (CNS; Fig. 10F,G). After 24 hpf, expression persisted in much of the CNS (retina, floor plate, etc.) and nonsomitic mesoderm (Fig. 10H,I). At later stages, anx13 was expressed throughout the embryo (data not shown), being the most widely expressed of all the anx genes.

\section{DISCUSSION}

The ANXs comprise a family of $\mathrm{Ca}^{2+}$ and phospholipid binding proteins that contain four or eight highly conserved repeating domains of $\sim 70$ amino acids (Seaton 1996). Data largely from cell culture studies indicate that ANXs are regulated by growth factor-mediated tyrosine phosphorylation (Brugge 1986; Huang et al. 1986) and by PKC phosphorylation (Schlaepfer et al. 1992; Minin et al. 1998; Schmitz-Peiffer et al. 1998). ANXs can inhibit phospholipase $A_{2}$ activity (Brugge 1986; Huang et al. 1986; Kim et al. 1994; Croxtal et al. 1996; Mira et al. 1997), form channels (Nilius et al. 1996), and regulate membrane trafficking (Donnelly and Moss 1997; Gerke and Moss 1997; Bandorowicz-Pikula and Pikula 1998; Kobayashi et al. 1998). It is likely ANXs play key roles in regulating a variety of signal transduction events. ANXs are also ubiquitous in eukaryotic cells and can represent $\geq 1 \%$ of total cell protein (Seaton 1996). Although there is now a body of literature describing the interesting properties of ANXs, their in vivo functions remain elusive.

As a first step toward exploring the function and evolution of the vertebrate anx gene family, we cloned 11 zebrafish anx genes by cDNA library screening and the analysis of zebrafish ESTs deposited in GenBank. In studying ANX evolution, the zebrafish has the advantage that there was a genome-wide duplication some 100 million years ago, well after fish and mammals diverged, followed by selective 
A

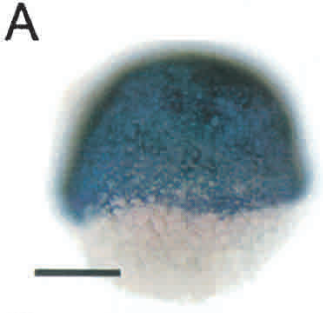

E

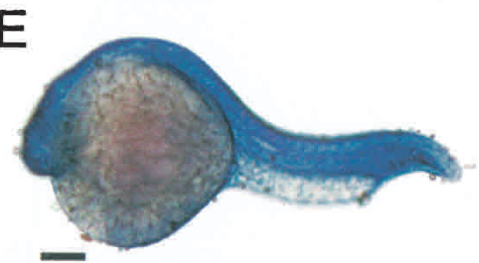

B
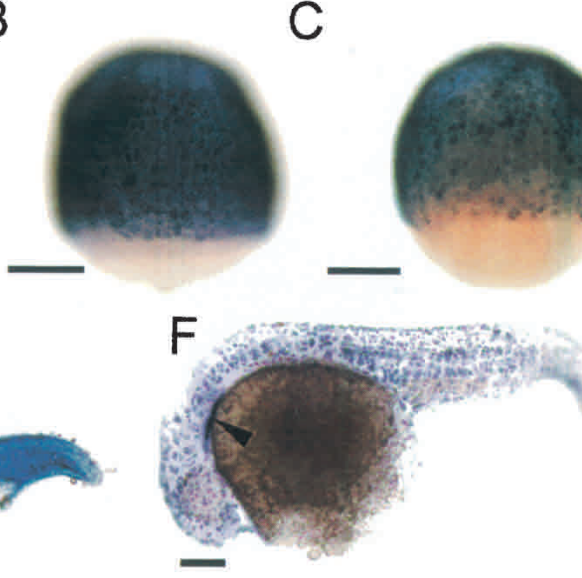

D
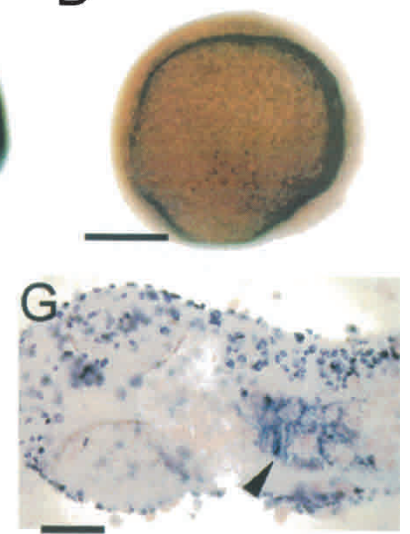

$\mathrm{H}$

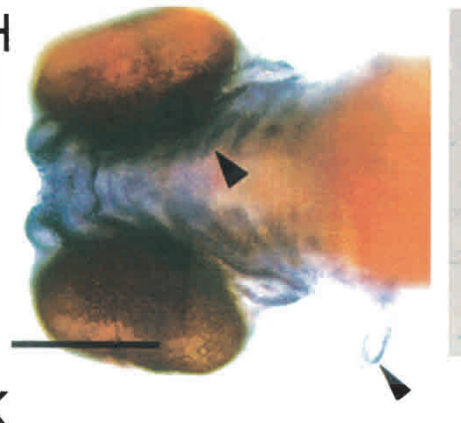

$\mathrm{K}$
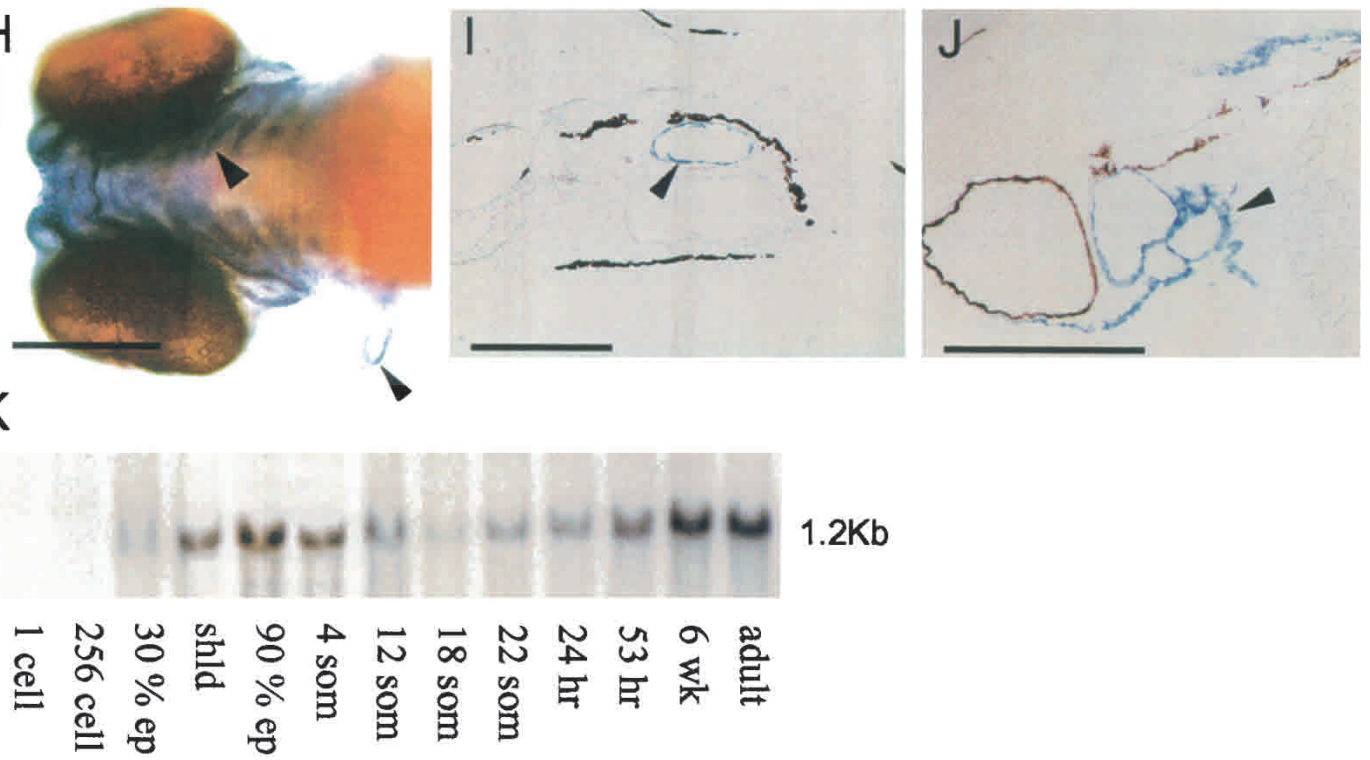

Figure 5 Expression of $a n x 1$ paralogs. ( $A-C)$ Lateral views of $70 \%$ epiboly stage embryos revealing enveloping layer expression of anx $1 a(A)$ anx $1 b(B)$, and $a n x 1 b(C) .(D) a n \times 1 a$ expression is markedly reduced by the 12 -somite stage and then reappears in the periderm $(E)$ at $24 \mathrm{hpf}$. $(F)$ Periderm expression of $a n \times 1 \mathrm{c}$ at $24 \mathrm{hpf}$. Arrowhead indicates a domain of anx1c expression not found with anx1a and anx1b. (G) A higher magnification dorsal view of the anx1c unique expression domain. A ventral view $(H)$ and sagittal section $(I)$ of 80 -hpf embryos showing anx1a expression in the gills, epithelium, fin buds, and the cells of the swim bladder (arrowhead). (J) At $80 \mathrm{hpf}$, anx $1 \mathrm{c}$ was expressed predominately in the epithelium. (K) Embryonic and adult expression of anx1 $a$ determined by Northern analysis. Total RNA was isolated from zebrafish embryos at selected stages from the one-cell stage to adult. Scale bar, $200 \mu \mathrm{m}$.

gene loss (Postlethwait et al. 1999). Thus, it is possible to study how sibling paralogs diverged in both sequence and expression.

Phylogenetic and BLAST analysis of the 11 anx genes indicated that zebrafish contain three paralogs of anx1, and duplicates of anx2 and anx11 (Figs. 2, 3). The prevailing view based on the study of mammalian anx genes is that the $\mathrm{N}$ terminal variable domain acts as a "fingerprint" to identify ANX family members (Moss 1992). The zebrafish data do not support this idea because the N-terminal domains have diverged so considerably that they were of little use in determining the correct ortholog (data not shown). This was in contrast to comparisons using the repeat domain. Once zebrafish genes were assigned to a particular ANX subtype, CLUSTAL alignments of the N-terminal domains with mammalian orthologs often revealed the conservation of key phosphorylation sites. In fact, the only recognizable homology in the N-terminal regions was in amino acids surrounding wellestablished regulatory domains important for phosphorylation.

To confirm that we had correctly identified a given zebrafish ANX, we localized each gene to the zebrafish genetic map. We were able to establish the identities of 10 of the 11 zebrafish genes by their position within syntenic gene clusters (Fig. 4). Four previously described medaka genes (max1, max2, max3, and max4) were also included in our phylogenetic comparisons. Sequence analysis indicated that medaka ortholog max 3 corresponds to zebrafish anx $1 a, \max 1$ to $a n x 4, \max 2$ to anx5, and max4 to anx $11 b$. Osterloh et al. (1998) observed the variability in the $\mathrm{N}$-terminal portion of the medaka proteins and concluded that max 3 and max4 were "novel" ANX family members. However, the zebrafish data clearly illustrates that anx $11 b$ (max4) maps to a region syntenic with human anx11. Similarly, the synteny data also reveals that $\max 1$ and $\max 2$

\section{Genome Research}



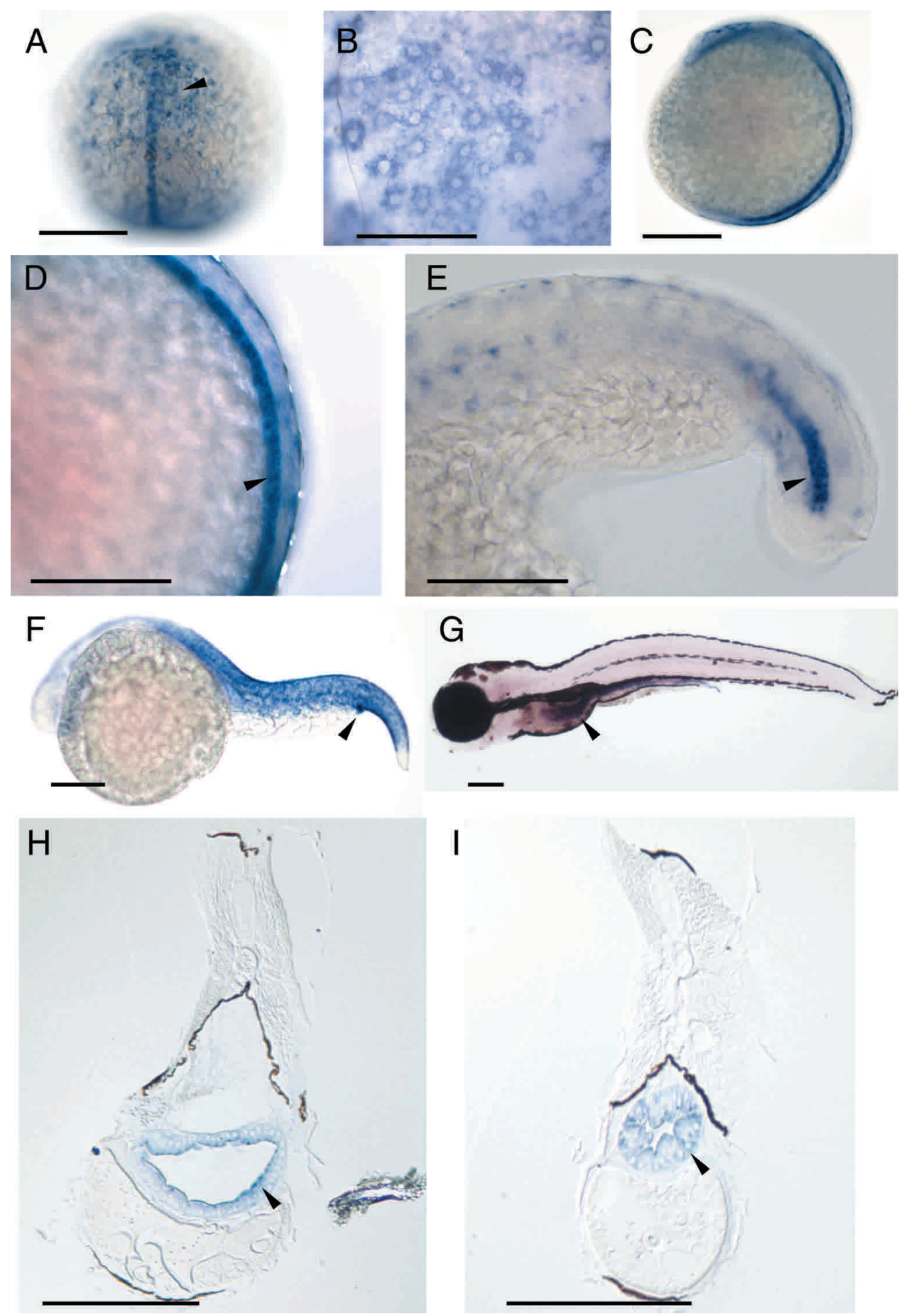

Figure 6 Expression of anx2 genes. (A) Dorsal view of a 100\% epiboly stage embryo revealing both notochord and enveloping layer expression (arrowhead) of $a n \times 2 a$. (B) Higher magnification view of embryo in A, highlighting enveloping layer expression. (C) A lateral view of notochord expression of $a n \times 2 a$ throughout the entire anterior to posterior axis; $(D)$ a higher power lateral view of the same embryo. $(E)$ A lateral view of a 21 -somite embryo with only posterior anx2a expression remaining. (F) At $24 \mathrm{hpf}$, anx2a expression is predominately in the periderm not notochord and then later in the skin (data not shown). (G) anx2b expression in the intestine at $72 \mathrm{hpf}$ (arrowhead). Sagittal sections through both the proximal $(H)$ and distal $(I)$ intestine indicate $a n \times 2 b$ expression in the apical brush border of the intestinal epithelium (arrowhead). 


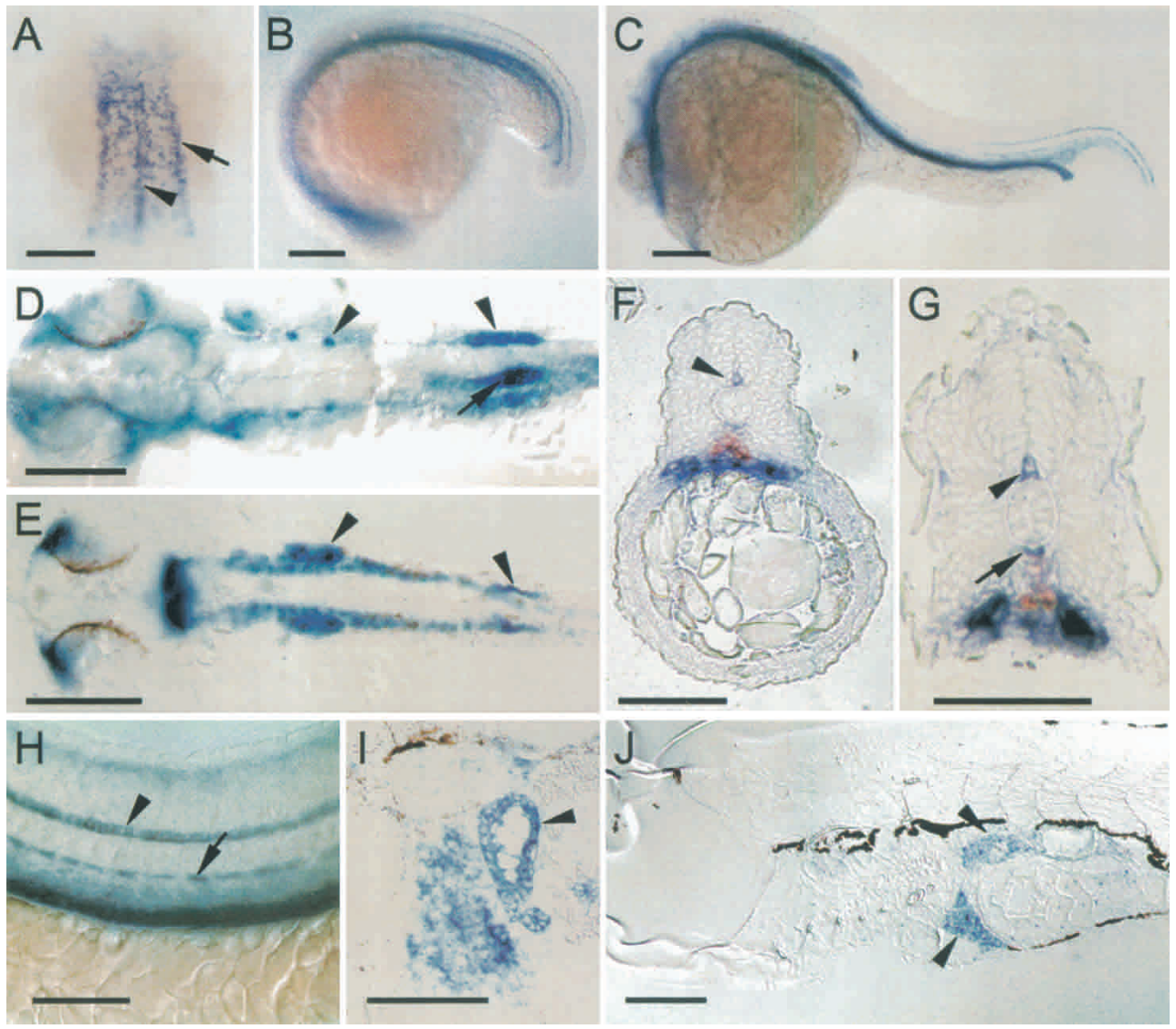

Figure 7 Expression of $a n x 4$. (A) Dorsal view of a four-somite embryo revealing anx4 transcripts in the floor plate (arrowhead) and in two lateral stripes (arrow) corresponding to pronephric duct precursor cells. Lateral views of a 21-somite (B) and a 24-hpf (C) embryo with prominent anx4 expression in the floor plate, hypochord, and pronephros. (D) Dorsal view at $24 \mathrm{hpf}$ also shows anx4 expression in the otolith, glomerulus (midline arrowhead), pronephric tubulues, and pronephric ducts. (E) A similar dorsal view illustrating pax2 transcripts in the otolith, pronephric tubulues, and pronephric ducts but not the glomerulus. Hematopoietic precursors were simultaneously visualized in cross sections using one riboprobe for draculin transcripts (red) and another for anx4 transcripts (blue) at both the 20-somite $(F)$ and $(G)$ 24-hpf stages. $(H)$ A lateral view at 24 hpf also localizes anx4 expression to floor plate (arrowhead), hypochord (arrow), and pronephros. Cross sections of 3-hpf larvae reveal anx4 expression predominately in the gall bladder $(I)$ and liver $(J)$. (A-E) Bar, $200 \mu \mathrm{m} ;(F-J)$ bar, $100 \mu \mathrm{m}$.

are orthologs of human anx4 and anx5, respectively. From these findings, a strong argument can be made that sequence comparisons need to be coupled with gene mapping and synteny data to understand the evolution of a complex multigene family such as the ANXs.

Increases in ploidy have been found for many cypriniform fish (Aparicio 1998), a group that includes the zebrafish. Although the zebrafish is diploid, its genome has retained $\sim 30 \%$ of the duplicated genes that occurred after fish and mammalian ancestors diverged, even though these genes were initially redundant (Amores et al. 1998; Postlethwait et al. 1998; Prince et al. 1998; Force et al. 1999). It is expected that, following duplication, redundant genes accumulate mutations that would rapidly transform one of the gene paralogs into a nonfunctional pseudogene. Although this certainly occurs in many cases, the rate of gene silencing is often much less than predicted by a number of genetic models (Meyer and Schartl 1999). The duplication-degenerationcomplementation (DDC) model has been proposed to explain the retention of duplicated genes (Force et al. 1999). This model considers the effect of mutations in noncoding regions, and predicts that if duplicate genes accumulate mutations in regulatory elements, then their expression might no longer overlap. Once expression between recently duplicated gene paralogs is nonredundant, it is more likely that the activity of both genes is now required to maintain the function of the single ancestral ortholog. Wagner (2000) suggests an alternative view that genes with overlapping or partially redundant functions might be maintained to offer protection from deleterious mutations. If one applies such models, then duplicated gene paralogs should have nonoverlapping aspects of their expression, and the combined expression patterns of recently duplicated paralogs should be consistent with the expression of a single mammalian ortholog.

Given the high degree of nucleotide identity and their proximity in the genome, anx $1 b$ and $a n \times 1 c$ most likely arose from a single gene that was subject to a more recent tandem duplication event (Fig. 4A). Even though these paralogs are 94\% identical in the first repeat, they have diverged extensively in their N-terminal domains (Fig. 2). This pattern was true for the other duplicated genes as well. Smith and Moss (1994) have argued that because these domains are "unique," they likely mediate the specific functions of each anx gene. If the accepted view that the ANX N-terminal domains defines ANX function holds, then these duplicated paralogs have evolved very different functions. Whether this hypothesis is 

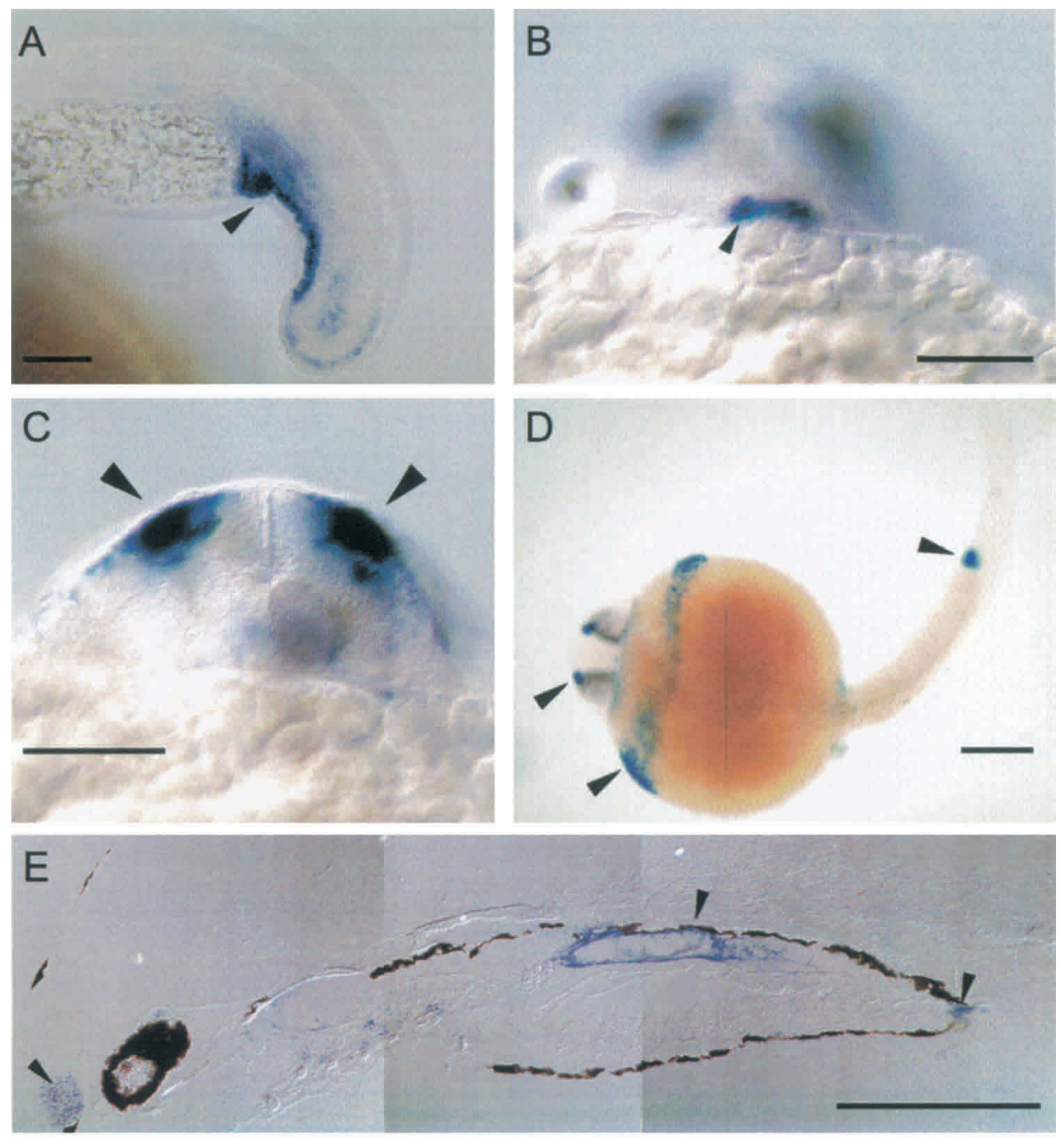

$\mathrm{F}$

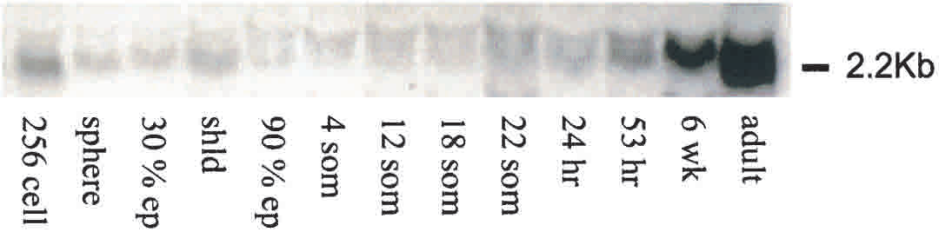

Figure 8 Expression of $a n \times 5$. (A) Lateral view of a 21-somite embryo revealing anx5 transcripts in blood island (arrowhead). Coronal view of a 26-somite embryo indicates anx5 expression in the most anterior domain $(B)$ and in the olfactory placodes (C). (D) Ventral view of a 24-hpf embryo reveals intense anx5 expression in the olfactory placodes, hatching gland cells, and anus. (E) Sagittal section through an 80-hpf larvae reveals expression in the developing nasal epithelium, anus, and swim bladder. ( $F$ ) Embryonic and adult expression of anx5 determined by Northern analysis. Total RNA was isolated from zebrafish embryos at selected stages from the one-cell stage to adult. $(A-C) B a r, 100 \mu \mathrm{m} ;(D, E)$ bar, $200 \mu \mathrm{m}$.

correct must await direct functional analysis of the sibling genes.

An analysis of the three zebrafish anx1 genes revealed that the ancestral anx1 gene common to both fish and mammals was duplicated most likely as a result of the predicted genome duplication event $>100$ million years ago. This resulted in anx1a near Z20915 and a second anx1 gene near marker coe2. This second anx1 gene was more recently dupli- cated to yield an additional anx gene at the coe2 locus as evidenced by the high degree of sequence homology between $a n \times 1 b$ and anx1c paralogs (Figs. 2A, 4A). Early in development, gene expression of all three anx1 paralogs was largely overlapping; however, by $24 \mathrm{hpf}$, differences emerged. Only anx1c was expressed in the anterior domain near the eyes and close to the yolk. However, it is possible that there are significant differences in expression levels of each anx1 

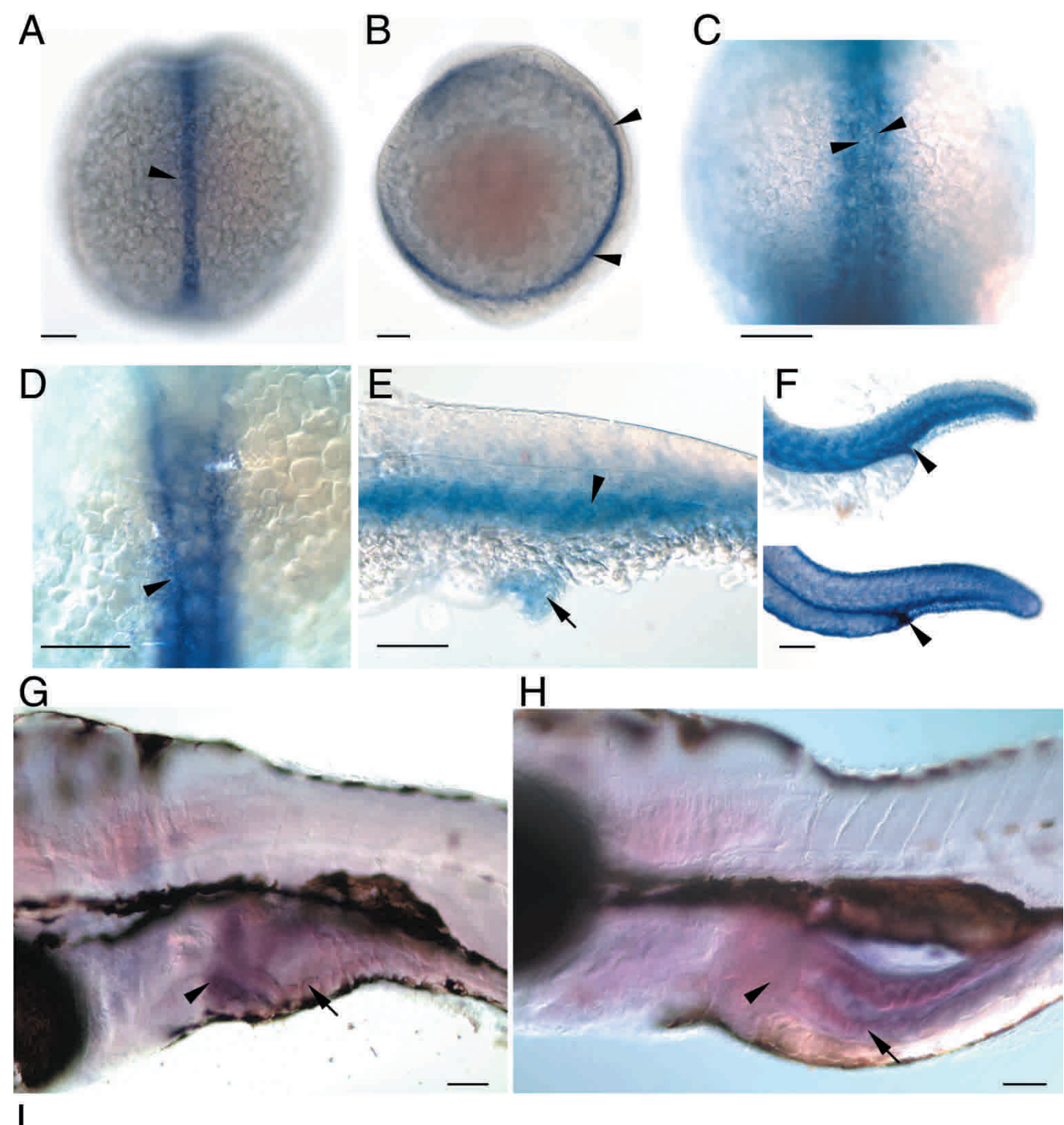

I

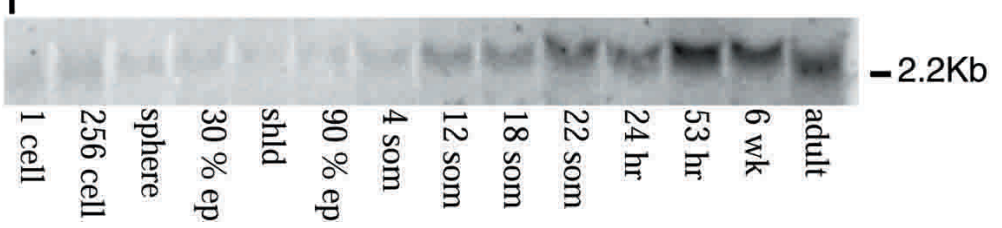

Figure 9 Expression of $a n x 11$ genes. Dorsal $(A)$ and lateral $(B)$ views of notochord anx $11 a$ expression in a four-somite embryo. (C, D) Dorsal views of 15-somite embryos illustrating a shift in anx11a expression from the axial mesoderm to the adaxial mesoderm that is also observed in embryos that lack differentiated notochord $\left(D ;\right.$ no tail $\left.{ }^{-I}\right)$. (E) By $24 \mathrm{hpf}$, anx 11 a expression was observed in the paraxial mesoderm (arrowhead) and anus (arrow). ( $(F)$ Lateral views of 24-hpf embryos reveal expression of both anx11a (top) and anx11b (bottom) in the periderm, arrowhead marks the anus. $(G, H)$ Lateral views of 80 -hpf larvae indicating greater levels of anx11a transcripts $(G)$ in the liver (arrowhead) than that of anx11b $(H)$. Embryonic and adult expression of anx $11 a$ determined by Northern analysis. (I) Total RNA was isolated from zebrafish embryos at selected stages from the one-cell stage to adult. Bar, $100 \mu \mathrm{m}$.

ortholog (as suggested by the time needed for staining; data not shown), something that can be more accurately quantified in further studies using quantitative reverse transcription-polymerase chain reaction (RT-PCR).

The overlap in expression of the anx2 paralogs was significantly different from that observed for the anx 1 genes. The anx 2 paralogs had no detectable overlap in expression, in that $a n \times 2 b$ transcripts were not detected until the onset of intestinal development ( $48 \mathrm{hpf}$ ), whereas anx $2 a$ was expressed dur- ing gastrulation in the notochord and later in the periderm (Fig. 6). Given that mammalian anx2 is expressed in both the skin and intestinal epithelium (Bastian et al. 1993; Ma and Ozers 1996; Munz et al. 1997; Dreier et al. 1998; Massey et al. 1998), it is likely that the expression of both zebrafish anx2 paralogs is required to provide the equivalent function of the human ortholog. Consistent with its selective role in intestinal physiology, preliminary data indicate that disruption of $a n \times 2 b$ translation by antisense injections at the one-cell stage

\section{Genome Research}


A

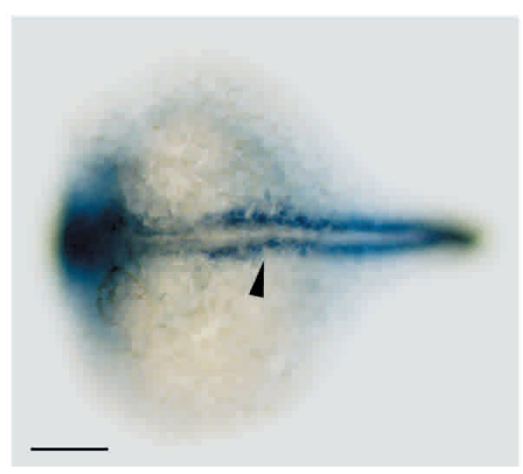

D

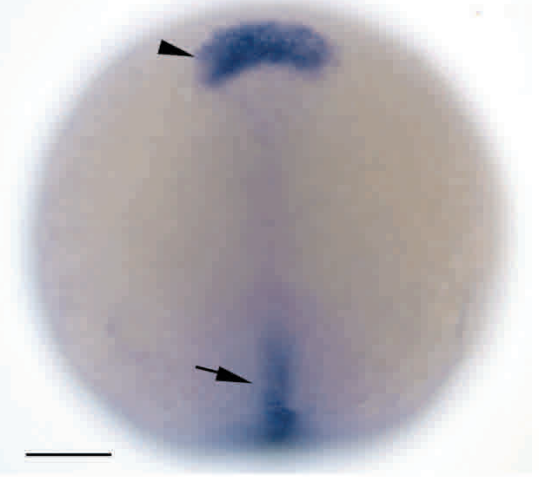

F

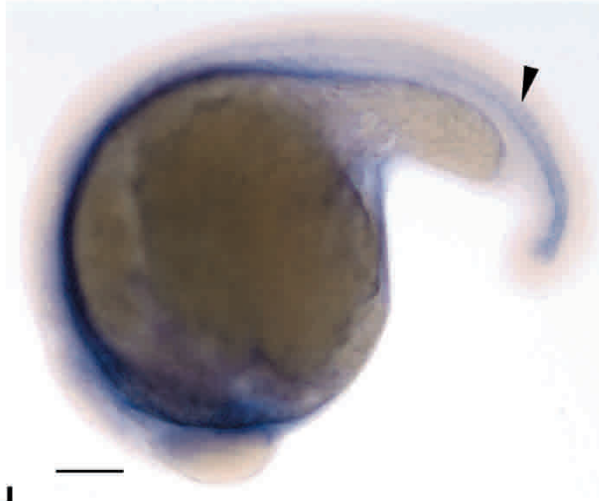

$\mathrm{H}$

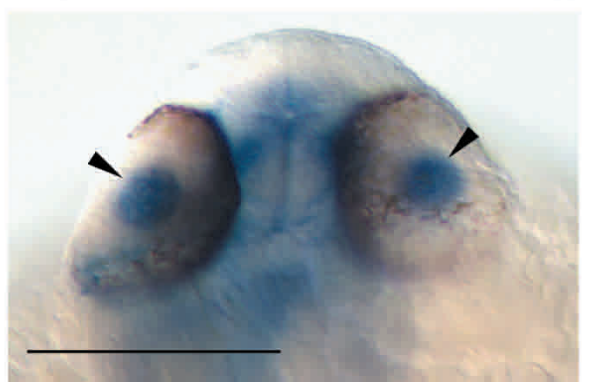

B

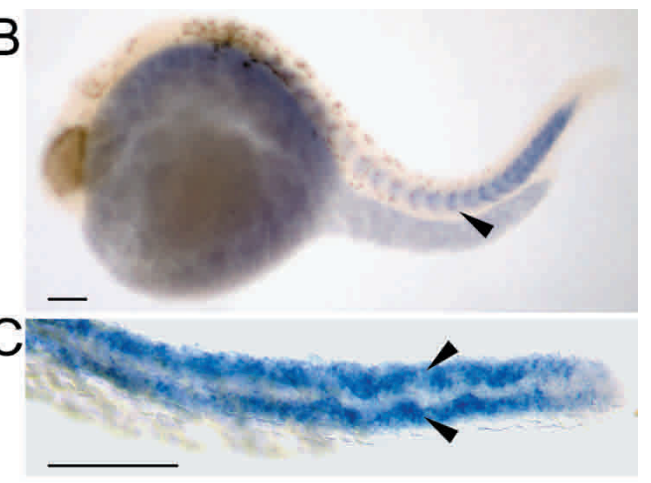

E

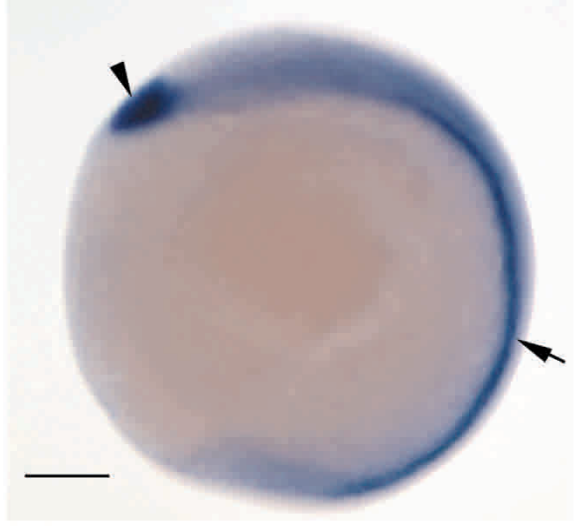

G
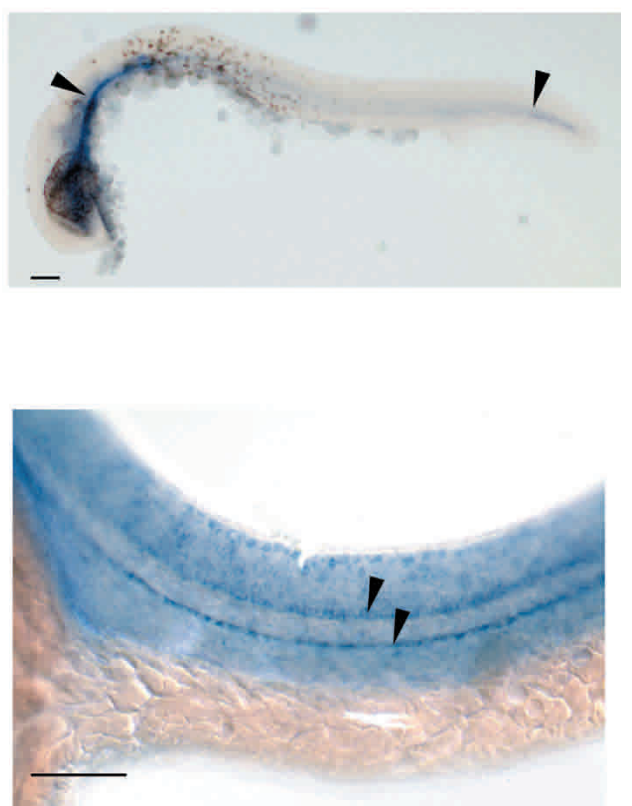

Figure 10 Expression of $a n x 6$ and $a n x 13$ genes. (A) Dorsal view of an 18-somite embryo reveals anx6 expression in somitic mesoderm. This pattern of anx6 expression continues through to $24 \mathrm{hpf}$, lateral view $(B)$ and dorsal view $(C)$. Dorsal $(D)$ and lateral $(E)$ views of anx13 expression in both the notochord (arrow) and polster (arrowhead) of bud stage embryos. Lateral views of 21-somite $(F)$ and 24-hpf $(G)$ embryos reveal that anx13 expression is maintained in the notochord and expands to the CNS. (H) Dorsal view at 24 hpf indicates anx13 expression in the retina (arrowhead). (I) Lateral view of the tail at this stage indicates notochord, floor plate, and nonsomitic mesoderm. Bar, $100 \mu \mathrm{m}$. 
profoundly affects cholesterol uptake, whereas disruption of anx $2 a$ does not (E. Smart, R. DeRose, and S. Farber, in prep.). A major effort to identify the specific amino acids mediating this effect is underway by examining the differences between the two zebrafish ANX2 paralogs identified in this study and by comparison to murine ANX2.

As was the case with anx2, anx11 paralogs exhibited significant differences in expression. Only anx $11 a$ was expressed during gastrulation (notochord) and somatogenesis (adaxial and paraxial mesoderm), whereas periderm expression was observed for both paralogs at $24 \mathrm{hpf}$ (Fig. 9A-F) After $80 \mathrm{hpf}$, anx $11 a$ was expressed more intensely in liver, whereas $a n \times 11 b$ was greater in intestine (Fig. 9G,H). The observation that duplicated zebrafish genes often have nonoverlapping expression patterns was also observed in a recent study of $\mathrm{Na}, \mathrm{K}-$ ATPases (Rajarao et al. 2001).

The observation that the evolutionary divergence between anx2 paralogs is clearly greater than that observed between $a n \times 1 b$ and anx $1 c$ paralogs not only indicates that the anx 1 gene duplication was a more recent event but illustrates how gene paralogs evolve. These studies have enabled us to focus our efforts on elucidating the function of both ANX2 and ANX4. Interestingly, ANX4 is expressed in the identical tissues (floor plate and kidney) of both zebrafish and mouse, in which analysis of the "knock out" phenotype is underway (J. Dedman, pers. comm.). Work is ongoing to compare the phenotypes observed with zebrafish ANX4 "morphants" with those observed in the mouse knock outs. With the availability of antisense techniques for the zebrafish, such as the injection of morpholino oligonucleotides (Nasevicius and Ekker 2000), it will be possible to assess further the redundant and nonoverlapping functions of particular ANXs.

\section{METHODS}

\section{Zebrafish}

Methods for breeding and raising zebrafish were followed as described (Westerfield 1995). Embryos were obtained from natural matings of wild-type (Oregon, $\mathrm{AB}$ ) fish and staged according to criteria previously outlined (Kimmel et al. 1995) and by hpf.

\section{Cloning of Zebrafish anx Genes}

PCR was used to amplify a 560-bp fragment of Xenopus laevis anx 2 from a random primed tadpole library (gift of D. Brown, Carnegie Institution of Washington, Maryland). Primer sequences were 5'-GAGCTGAAGG CTTCAATG-3' (forward) and 5'-GTCTAACTCACTTCGTGAAAC-3' (reverse). A ${ }^{32}$ P-labeled DNA probe, prepared by random priming of the gel-purified amplification product (Prime-It II; Stratagene), was used to screen a zebrafish postsomite stage cDNA library (gift of D. Grunwald, University of Utah Medical School, Utah) at low stringency (Sambrook et al. 1989). The protein sequences of the four zebrafish ANXs obtained from this screen were used for BLAST searches (Altschul et al. 1994) of $>73,000$ zebrafish EST sequences generated by the Zebrafish Genome Resources Project. The 212 anx EST sequences identified were clustered by using AssemblyLIGN software (Oxford Molecular Group). From this analysis, some unique clones were obtained commercially (Research Genetics) for complete DNA sequencing.

Seven additional anx clones were identified from the EST analysis. Two potential cloning artifacts were observed in commercially obtained clones. In the case of $a n \times 2 b$ (clone fb57f04), the $5^{\prime}$ end was disrupted by a repetitive element. The correct missing $5^{\prime}$ sequence was obtained by using RACE (Frohman et al. 1988). The primer sequences were $5^{\prime}$ CTCTTTATTGCGAGAACACACCAT-3', 5'-CATTCAACTAGT GTGAGGAAGG-3', and 5'-CTCTCTCCCCTCCATAACTCA-3'.

The commercially obtained anx13 clone (fb40a08) contained a shorter-than-expected open reading frame that appeared to be the result of a frame-shift mutation. To determine the correct anx13 sequence, PCR was used to amplify a fragment from genomic DNA to find if it contained the frame shift (primer sequences, 5'-GGAGCCGGAACCGAT GAAGAC-3' and 5'-GGAGGCGCTTG AAATCGCCTCCG-3'). After PCR, the fragment was gel purified and directly sequenced to reveal that the anx13 frame-shift mutation was a cloning artifact.

Sequences of all zebrafish anx genes described in this paper have been deposited in GenBank. The accession nos. are as follows: anx1a, AY178793; anx1b, AY178794; anx1c, $\mathrm{AY} 178795$; anx2a, AY178796; anx2b, AY178797; anx4,

Table 2. Mapping Primers

\begin{tabular}{|c|c|c|c|c|c|c|}
\hline \multirow[b]{2}{*}{ Gene } & \multirow{2}{*}{$\begin{array}{c}\text { Primer } 1 \\
5^{\prime} \rightarrow 3^{\prime}\end{array}$} & \multirow{2}{*}{$\begin{array}{c}\text { Primer } 2 \\
5^{\prime} \rightarrow 3^{\prime}\end{array}$} & \multirow{2}{*}{$\begin{array}{l}\text { Linkage } \\
\text { group }\end{array}$} & \multicolumn{2}{|c|}{ Flanking markers } & \multirow{2}{*}{$\begin{array}{l}\text { Distance from } \\
\text { marker } 1 \\
\text { cR (LOD) }\end{array}$} \\
\hline & & & & Marker 1 & Marker 2 & \\
\hline anx $1 a$ & - & - & 5 & Z20915 & Z21461 & $0.4(>10)^{a}$ \\
\hline$a n \times 1 b$ & СTCCCCTGGATTTTGAAACAT & CAGAAGAAAGGCAAACAGG & 5 & Z23067 & coe2 & 4 (17.3) \\
\hline$a n \times 1 b$ & ACAACGAGATCAAAGCCAT & CCTCCAGCAGCTCCCCATA & 5 & Z23067 & coe2 & 2 (15.9) \\
\hline anx $1 c$ & GCTCTGTTTGAGGCAGGAGAG & CAGGCAGTCTTCAAGGTGTCCAC & 5 & Z23067 & coe2 & $4.3(14.3)$ \\
\hline anx $1 c$ & GCTCTGTTTGAGGCAGGAGAG & AACCATCTTTGCTTAATTGGC & 5 & Z23067 & coe2 & $4.5(14.7)$ \\
\hline$a n \times 2 a$ & $\begin{array}{l}\text { GTTCAGTGCTTTGAAAACAAACAGC } \\
\text { TGTATTTCGCC }\end{array}$ & GGACACCATGATCCGGGTCAGCAC & 25 & mariposa & Z15401 & $10(15.7)$ \\
\hline$a n \times 2 b$ & GTGTGAAAGACAAGATAATAACC & TGAAATTGTCTGGTGCAGAGATC & 7 & Z20853 & Z11119 & $13(15.4)$ \\
\hline anx 4 & GAACATGACAAGAGTCTTGAAGAC & CTTTGCATCCTGGACAGCCTGAG & 10 & Z14193 & Z6992 & $2(19.0)$ \\
\hline an $\times 5$ & CTGAATCATTTTGTGCAGGG & GGGGCAGGCACTGACGATCAGACA & 1 & Z1463 & Z7287 & $10(14.4)$ \\
\hline anx 6 & GCACGGACTGATGAACATGCG & CTGTGCCAGTGAGATCAGG & 14 & Z6674 & Z3984 & $40(13.2)$ \\
\hline anx $11 a$ & GTGTTTAATGAGTACCAGCACATG & GACAGCCAGCATGCCGCTCTC & 13 & Z13682 & Z9049 & $35(12.1)$ \\
\hline$a n \times 11 b$ & GTGACTGAAGAGCAGGAGG & GCAAAGTATTTCTTGATTTCTC & 12 & Z4634 & Z8254 & $5(17.9)$ \\
\hline anx 13 & GGAGCCGGAACCGATGAAGAC & GGAGGCGCTTGAAATCGCCTCCG & 24 & Z5413 & Z23011 & $21(11.4)$ \\
\hline
\end{tabular}

\section{Genome Research


AY178798; anx5, AY178799; anx6, AY178800; anx11a, AY178801; anx11b, AY178802; and anx13, AY178803.

\section{anx Gene Evolution}

A phylogenetic trees showing the evolutionary relationship of the anx genes was produced using MacVector software (Accelrys). The final tree was determined by using UPGMA with ties resolved randomly by using 1000 bootstrap replications. Percentages represent the occurrence of the nodes. Trees were calculated from comparisons of the first 73-83 amino acids of the first ANX repeat.

\section{Mapping and Syntenic Analysis}

Zebrafish anxs were mapped using the LN54 Radiation Hybrid Panel as previously described (Hukriede et al. 1999). Primers for each gene are noted in Table 2 . To determine syntenic relationships between zebrafish and human genomes, mapped zebrafish genes flanking a particular zebrafish anx gene were identified (maps used were Mother of Pearl Meiotic Map, GAT Meiotic Map, LN54 Radiation Hybrid Map; for map data, see http://zfin.org/cgi-bin/webdriver?Mlval=aarefcrosslist.apg). The protein sequences of the flanking genes were used to identify human orthologs by BLAST searches. The chromosomal locations of human orthologs were determined by searching either the Human Gene Map99 Project or the Human Gene Database.

To confirm that the mapping of $a n \times 1 b$ and $a n \times 1 c$ to the same locus was not due to a PCR artifact (primers for one paralog actually amplify the other paralog), two sets of primers were used for each gene (Table 1), in which one set was designed in a region of the 3'UTR that was not similar between the sibling genes. Furthermore, a number of PCR products from the mapping reactions were cut from the mapping gel and directly sequenced, confirming that primers for $a n \times 1 b$ were not amplifying anx1c and vice versa (data not shown).

\section{Northern Analysis}

For some anx genes (anx1a, anx2a, anx5, and anx11a), mRNA levels were detected by Northern analysis of total RNA (Sambrook et al. 1989) using a ${ }^{32}$ P-labeled anx probe prepared by random priming of gel-purified zebrafish anx cDNAs (Prime-It II; Stratagene) and compared with expression observed with RNA in situ hybridization.

\section{RNA In Situ Hybridization}

In situ hybridization for anx expression was carried out as previously described (Thisse et al. 1993). Digoxigenin-labeled RNA probes synthesized for each gene were hybridized to embryos or larvae at $50 \%$ epiboly, $100 \%$ epiboly, tail bud, 1 somite, 5 somites, 15 somites, 20 somites, $24 \mathrm{hpf}, 48 \mathrm{hpf}$, and 72 hpf. For double-labeled in situ hybridizations, probes were synthesized with either digoxigenin- or fluoresceinconjugated UTP and detected as previously described (Sagerstrom et al. 1996). After visualization, some embryos older than $24 \mathrm{~h}$ were refixed in $4 \%$ paraformaldehyde and sectioned as described (Westerfield, 1995).

\section{ACKNOWLEDGMENTS}

S.A.F was supported by an NRSA and Barbara McClintock Fellowship (Carnegie Institution); M.E.H., by a Pew's Scholar's Award. We also appreciated the helpful comments provided by Dr. John Dedman.

The publication costs of this article were defrayed in part by payment of page charges. This article must therefore be hereby marked "advertisement" in accordance with 18 USC section 1734 solely to indicate this fact.

\section{REFFERENCES}

Altschul, S., Boguski, M., Gish, W., and Wootton, J. 1994. Issues in searching molecular sequence databases. Nat. Genet. 6: 119-129.

Amores, A., Force, A., Yan, Y., Joly, L., Amemiya, C., Fritz, A., Ho, R., Langeland, J., Prince, V., Wang, Y., et al. 1998. Zebrafish hox clusters and vertebrate genome evolution. Science 282: $1711-1714$.

Aparicio, S. 1998. Exploding vertebrate genomes. Nat. Genet. 18: $301-303$.

Bandorowicz-Pikula, J. and Pikula, S. 1998. Annexins and ATP in membrane traffic: A comparison with membrane fusion machinery. Acta Biochim. Pol. 45: 721-733.

Bastian, B., van der Piepen, U., Romisch, J., Paques, E., and Brocker, E. 1993. Localization of annexins in normal and diseased human skin. J. Dermatol. Sci. 6: 225-234.

Bonfils, C., Greenwood, M., and Tsang, A. 1994. Expression and characterization of a Dictyostelium discoideum annexin. Mol. Cell. Biochem. 139: 159-166.

Brugge, J.S. 1986. The p35/p36 substrates of protein-tyrosine kinases as inhibitors of phospholipase A2. Cell 46: 149-150.

Creutz, C.E. 1981. cis-Unsaturated fatty acids induce the fusion of chromaffin granules aggregated by synexin. J. Cell. Biol. 91: 247-256.

Creutz, C.E., Snyder, S.L., Daigle, S.N., and Redick, J. 1996. Identification, localization, and functional implications of an abundant nematode annexin. J. Cell. Biol. 132: 1079-1092.

Croxtal, J.D., Newman, S.P., Choudhury, Q., and Flower, R.J. 1996. The concerted regulation of CPLA2, COX2, and lipocortin 1 expression by IL-1 $\beta$ in A549 cells. Biochem. Biophys. Res. Commun. 220: 491-495.

Davidson, F.F., Dennis, E.A., Powell, M., and Glenney Jr., J.R. 1987. Inhibition of phospholipase A2 by "lipocortins" and calpactins: An effect of binding to substrate phospholipids. J. Biol. Chem. 262: $1698-1705$.

Davidson, F.F., Lister, M.D., and Dennis, E.A. 1990. Binding and inhibition studies on lipocortins using phosphatidylcholine vesicles and phospholipase A2 from snake venom, pancreas, and a macrophage-like cell line. J. Biol. Chem. 265: 5602-5609.

de Coupade, C., Gillet, R., Bennoun, M., Briand, P., Russo-Marie, F., and Solito, E. 2000. Annexin 1 expression and phosphorylation are upregulated during liver regeneration and transformation in antithrombin III SV40 T large antigen transgenic mice. Hepatology 31: 371-380.

Donnelly, S. and Moss, S. 1997. Annexins in the secretory pathway. Cell. Mol. Life Sci. 53: 533-538.

Dreier, R., Schmid, K., Gerke, V., and Riehemann, K. 1998. Differential expression of annexins I, II and IV in human tissues: An immunohistochemical study. Histochem. Cell. Biol. 110: $137-148$.

Drummond, I., Majumdar, A., Hentschel, H., Elger, M., Solnica, K.L., Schier, A., Neuhauss, S., Stemple, D., Zwartkruis, F., Rangini, Z., et al. 1998. Early development of the zebrafish pronephros and analysis of mutations affecting pronephric function. Development 125: $4655-4667$

Emans, N., Gorvel, J.P., Walter, C., Gerke, V., Kellner, R., Griffiths, G., and Gruenberg, J. 1993. Annexin II is a major component of fusogenic endosomal vesicles. J. Cell. Biol. 120: 1357-1369.

Fiedler, K. and Simons, K. 1995. Annexin homologues in Giardia lamblia. Trends Biochem. Sci. 20: $177-178$.

Force, A., Lynch, M., Pickett, F., Amores, A., Yan, Y., and Postlethwait, J. 1999. Preservation of duplicate genes by complementary, degenerative mutations. Genetics 151: $1531-1545$.

Frohman, M., Dush, M., and Martin, G. 1988. Rapid production of full-length cDNAs from rare transcripts: Amplification using a single gene-specific oligonucleotide primer. Proc. Natl. Acad. Sci. 85: 8998-9002.

Gerke, V. and Moss, S. 1997. Annexins and membrane dynamics. Biochim. Biophys. Acta 1357: 129-154.

Glenney Jr., J.R. 1985. Phosphorylation of p36 in vitro with pp60src: Regulation by $\mathrm{Ca}^{2+}$ and phospholipid. FEBS Lett. 192: 79-82.

Halpern, M.E., Ho, R.K., Walker, C., and Kimmel, C.B. 1993 Induction of muscle pioneers and floor plate is distinguished by the zebrafish no tail mutation. Cell 75: 99-111.

Herbomel, P., Thisse, B., and Thisse, C. 1999. Ontogeny and behaviour of early macrophages in the zebrafish embryo. Development 126: 3735-3745.

Huang, K.S., Wallner, B.P., Mattaliano, R.J., Tizard, R., and Burne, C. 1986. Two human 35-kd inhibitors of phospholipase A2 are 
related to substrates of pp60v-src and of the epidermal growth factor receptor/kinase. Cell 46: 191-199.

Hukriede, N., Joly, L., Tsang, M., Miles, J., Tellis, P., Epstein, J., Barbazuk, W., Li, F., Paw, B., Postlethwait, J., et al. 1999. Radiation hybrid mapping of the zebrafish genome. Proc. Natl. Acad. Sci. 96: 9745-9750.

Johnston, P.A., Perin, M.S., Reynolds, G.A., Wasserman, S.A., and Sudhof, T.C. 1990. Two novel annexins from Drosophila melanogaster: Cloning, characterization, and differential expression in development. J. Biol. Chem. 265: 11382-11388.

Kaetzel, M., Chan, H., Dubinsky, W., Dedman, J., and Nelson, D. 1994. A role for annexin IV in epithelial cell function: Inhibition of calcium-activated chloride conductance. J. Biol. Chem. 269: 5297-5302.

Kim, K.M., Kim, D.K., Park, Y.M., Kim, C.K., and Na, D.S. 1994. Annexin-I inhibits phospholipase A2 by specific interaction, not by substrate depletion. FEBS Lett. 343: 251-255.

Kimmel, C., Ballard, W., Kimmel, S., Ullmann, B., and Schilling, T. 1995. Stages of embryonic development of the zebrafish. Dev. Dyn. 203: 253-310.

Kobayashi, T., Gu, F., and Gruenberg, J. 1998. Lipids, lipid domains and lipid-protein interactions in endocytic membrane traffic. Semin. Cell. Dev. Biol. 9: 517-526.

Konig, J., Prenen, J., Nilius, B., and Gerke, V. 1998. The annexin II-p11 complex is involved in regulated exocytosis in bovine pulmonary artery endothelial cells. J. Biol. Chem. 273: $19679-19684$

Ma, A. and Ozers, L. 1996. Annexins I and II show differences in subcellular localization and differentiation-related changes in human epidermal keratinocytes. Arch. Dermatol. Res. 288: $596-603$.

Massey, H.D., Mayran, N., and Maroux, S. 1998. Polarized localizations of annexins I, II, VI and XIII in epithelial cells of intestinal, hepatic and pancreatic tissues. J. Cell. Sci. 111: $3007-3015$.

Meyer, A. and Schartl, M. 1999. Gene and genome duplications in vertebrates: The one-to-four (-to-eight in fish) rule and the evolution of novel gene functions. Curr. Opin. Cell. Biol. 11: $699-704$

Minin, A.A., Zemskov, E.A., and Khaidarova, N.V. 1998. Protein kinase $C$ and casein kinase 2 phosphorylate in vitro proteins of the annexin family from eggs of loach Misgurnus fossilis. Biochemistry (Mosc.) 63: 1074-1077.

Mira, J.P., Dubois, T., Oudinet, J.P., Lukowski, S., Russo-Marie, F., and Geny, B. 1997. Inhibition of cytosolic phospholipase A2 by annexin V in differentiated permeabilized HL-60 cells: Evidence of crucial importance of domain I type II Ca ${ }^{2+}$-binding site in the mechanism of inhibition. J. Biol. Chem. 272: 10474-10482.

Morgan, R.O. and Fernandez, M.P. 1997. Annexin gene structures and molecular evolutionary genetics. Cell. Mol. Life Sci. 53: $508-515$.

Morgan, R.O. and Pilar Fernandez, M. 1997. Distinct annexin subfamilies in plants and protists diverged prior to animal annexins and from a common ancestor. J. Mol. Evol. 44: $178-188$

Morgan, R.O., Jenkins, N.A., Gilbert, D.J., Copeland, N.G., Balsara, B.R., Testa, J.R., and Fernandez, M.P. 1999. Novel human and mouse annexin A10 are linked to the genome duplications during early chordate evolution. Genomics 60: 40-49.

Moss, S. 1992, The annexins. In: The annexins (ed. S.E. Moss), pp. 1-10. Portland Press, Chapel Hill, NC.

Munz, B., Gerke, V., Gillitzer, R., and Werner, S. 1997. Differential expression of the calpactin I subunits annexin II and p11 in cultured keratinocytes and during wound repair. J. Invest. Dermatol. 108: 307-312.

Nasevicius, A. and Ekker, S.C. 2000. Effective targeted gene "knockdown" in zebrafish. Nat. Genet. 26: 216-220.

Nilius, B., Gerke, V., Prenen, J., Szucs, G., Heinke, S., Weber, K., and Droogmans, G. 1996. Annexin II modulates volume-activated chloride currents in vascular endothelial cells. J. Biol. Chem. 271: 30631-30636.
Osterloh, D., Wittbrodt, J., and Gerke, V. 1998. Characterization and developmentally regulated expression of four annexins in the killifish medaka. DNA Cell Biol. 17: 835-847.

Postlethwait, J., Yan, Y., Gates, M., Horne, S., Amores, A., Brownlie, A., Donovan, A., Egan, E., Force, A., Gong, Z., et al. 1998. Vertebrate genome evolution and the zebrafish gene map. Nat. Genet. 18: 345-349.

Postlethwait, J., Amores, A., Force, A., and Yan, Y. 1999. The zebrafish genome. Methods Cell. Biol. 60: 149-163.

Prince, V.E., Joly, L., Ekker, M., and Ho, R.K. 1998. Zebrafish hox genes: Genomic organization and modified colinear expression patterns in the trunk. Development 125: 407-420.

Rajarao, S.J., Canfield, V.A., Mohideen, M.A., Yan, Y.L., Postlethwait, J.H., Cheng, K.C., and Levenson, R. 2001. The repertoire of $\mathrm{Na}, \mathrm{K}-\mathrm{ATPa} e \mathrm{\alpha}$ and $\beta$ subunit genes expressed in the zebrafish, Danio rerio. Genome Res. 11: 1211-1220.

Raynor, C.M., Wright, J.F., Waisman, D.M., and Pryzdial, E.L. 1999. Annexin II enhances cytomegalovirus binding and fusion to phospholipid membranes. Biochemistry 38: 5089-5095.

Sagerstrom, C., Grinbalt, Y., and Sive, H. 1996. Anteroposterior patterning in the zebrafish, Danio rerio: An explant assay reveals inductive and suppressive cell interactions. Development 122: $1873-1883$.

Sambrook, J., Fritsch, E., and Maniatis, T., 1989. Molecular cloning: A laboratory manual. Cold Spring Harbor Press, Cold Spring Harbor, NY.

Schlaepfer, D.D., Fisher, D.A., Brandt, M.E., Bode, H.R., Jones, J.M., and Haigler, H.T. 1992. Identification of a novel annexin in Hydra vulgaris: Characterization, cDNA cloning, and protein kinase C phosphorylation of annexin XII. J. Biol. Chem. 267: 9529-9539.

Schmitz-Peiffer, C., Browne, C.L., Walker, J.H., and Biden, T.J. 1998. Activated protein kinase $\mathrm{C} \alpha$ associates with annexin VI from skeletal muscle. Biochem. J. 330: 675-681.

Seaton, B. 1996. Annexins: Molecular structure to cellular function. R.G. Landes Company, Austin, TX.

Smallwood, M.F., Gurr, S.J., Choudhari, U., and Bowles, D.J. 1990a. Characterization of plant annexin gene expression. Biochem. Soc. Trans. 18: 1116

Smallwood, M., Keen, J.N., and Bowles, D.J. 1990b. Purification and partial sequence analysis of plant annexins. Biochem. J. 270: $157-161$

Smith, P. and Moss, S. 1994. Structural evolution of the annexin supergene family. Trends Genet. 10: 241-246.

Thisse, C., Thisse, B., Schilling, T., and Postlethwait, J. 1993. Structure of the zebrafish snail1 gene and its expression in wild-type, spadetail and no tail mutant embryos. Development 119: $1203-1215$.

Tokumitsu, H., Mizutani, A., Minami, H., Kobayashi, R., and Hidaka, H. 1992. A calcyclin-associated protein is a newly identified member of the $\mathrm{Ca}^{2+} /$ phospholipid-binding proteins, annexin family. J. Biol. Chem. 267: 8919-8924.

Wagner, A. 2000. The role of population size, pleiotropy and fitness effects of mutations in the evolution of overlapping gene functions. Genetics 154: 1389-1401.

Weinberg, E.S., Allende, M.L., Kelly, C.S., Abdelhamid, A., Murakami, T., Andermann, P., Doerre, O.G., Grunwald, D.J., and Riggleman, B. 1996. Developmental regulation of zebrafish MyoD in wild-type, no tail and spadetail embryos. Development 122: 271-280.

Westerfield, M., 1995. The zebrafish book. University of Oregon, Eugene, OR.

\section{WEB SITE REFERENCES}

http://zfin.org/cgi-bin/webdriver?Mlval=aa-refcrosslist.apg; Listing of zebrafish mapping panels.

Received May 30, 2002; accepted in revised form April 7, 2003.

\section{Genome Research}




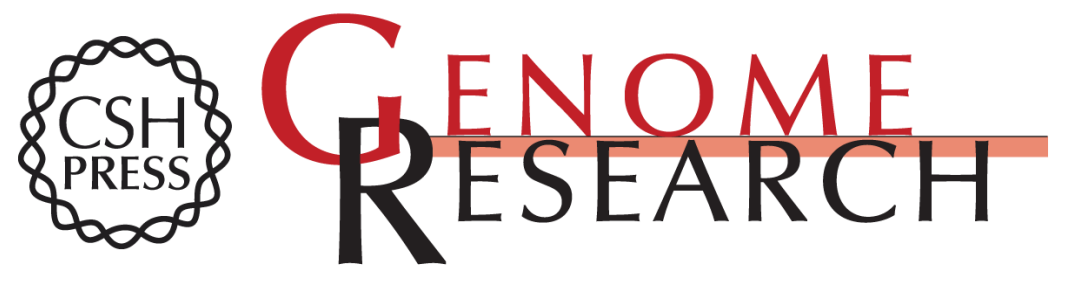

\section{The Zebrafish Annexin Gene Family}

Steven A. Farber, Robert A. De Rose, Eric S. Olson, et al.

Genome Res. 2003 13: 1082-1096

Access the most recent version at doi:10.1101/gr.479603

References This article cites 58 articles, 26 of which can be accessed free at:

http://genome.cshlp.org/content/13/6a/1082.full.html\#ref-list-1

License

Email Alerting Receive free email alerts when new articles cite this article - sign up in the box at the Service top right corner of the article or click here.

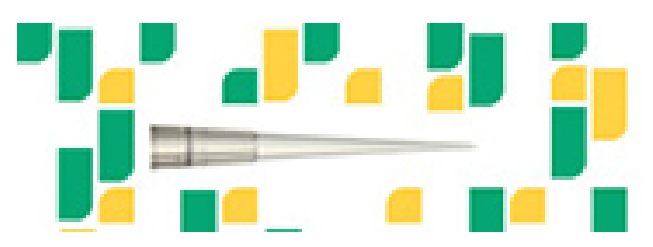

To subscribe to Genome Research go to: https://genome.cshlp.org/subscriptions 